\title{
ACUMULAÇÃO DIFERENCIAL DE NUTRIENTES POR CINCO CULTIVARES DE MILHO (Zea mays L.). I - ACUMULAÇÃO DE MACRONUTRIENTES *
}

\author{
A.G. DE ANDRADE** \\ H.P. HAAG *** \\ G.D. DE OLIVEIRA*** \\ J.R. SARRUGE***
}

\section{RESUMO}

No presente trabalho, os autores apresentam os resultados de um ensaio de campo empregando os cultivares Agroceres 256, Agroceres 504, Centralmex, H-7974 e Piranão no sentido de aquilatar diferenças no crescimento, produção e acumulação e exportação de nutrientes. $\mathrm{O}$ ensaio foi conduzido num regossol de fertilidade mediana, exceto em relação ao K que é baixo, situado no Município de Piracicaba, SP. O delineamento experimental utilizado foi de blocos ao acaso com 4 repetições. Foram seguidas as práticas culturais comuns, e a adubação constituiu de $83 \mathrm{~g}$ da fórmula $30-120-70$ por metro linear por ocasião do plantio e $33 \mathrm{~g}$ por metro linear da fórmula 50-0-4, em cobertura 22 dias após a germinação. Plantas foram coletadas a partir dos 20 dias após a germinação, em intervalos de 20 dias até os 120 dias. As plantas foram divididas em "colmo + folhas", pendão e espiga e analisadas para $\mathrm{N}, \mathrm{P}, \mathrm{K}, \mathrm{Ca}, \mathrm{Mg}$ e $\mathrm{S}$. Concluíram os autores que diferenças entre cultivares na acumulação de matéria seca na parte vegetativa não se traduzem, necessariamente, por um aumento de peso da matéria seca na espiga. Os cultivares atingem o máximo da quantidade de nutrientes nas seguintes épocas, em dias: N (89-100); P (101-120); K (58-66); Ca (74-94); $\mathrm{Mg}(100-120)$; S (93-95). Verificaram, ainda, que as quantidades máximas extraídas em $\mathrm{mg} /$ planta são: $\mathrm{N}$ (3169-3878); P (541-642); K (3850-4693); Ca (582-782); Mg (654-943); S (444-799). Finalmente a exportação de nutrientes nas espigas por hectare $(50.000$ plan. tas) colhidas é: $\mathrm{N}(111-143 \mathrm{~kg}) ; \mathrm{P}(22-30 \mathrm{~kg}) ; \mathrm{Ca}(0,7-1,1 \mathrm{~kg}) ; \mathrm{Mg}$ $(10-12 \mathrm{~kg}) ; \mathrm{S}(9-13 \mathrm{~kg})$.

\section{INTRODUÇÃO}

O milho é uma das plantas mais estudadas do ponto de vista nutricional, provavelmente pela sua importância na alimentação humana, ciclo relativamente curto e pela quantidade de conhecimento já existente. No entanto, a maior parte dos estudos sãc feitos em países de clima temperado, e nem sempre podem ser extrapolados para as condições tropicais (KRUG, 1966).

* Parte da dissertação apresentada pelo primeiro autor para obtenção do grau de MESTRE pela E.S.A. "Luiz de Queiroz", USP. Suporte financeiro da EMBRAPA, Brasília-DF. Entregue para publicação em 22/7/1975.

* Universidade Federal Rural de Pernambuco, Recife-PE.

*** E.S.A. “Luiz de Queiroz”, USP - Depto. de Química, Piracicaba-SP. 
Segundo NELSON (1956), foi Hornberger, em 1822, quem estudou pela primeira vez a acumulação de materiais orgânicos e inorgânicos durante o desenvolvimento da planta. BUCKNER (1915), menciona, que $2 / 3$ dos elementos minerais localizados na semente são translocados para o "seedling", e dão para sustentá-lo até cerca de 23 dias após a emergência.

No entanto, o primeiro trabalho expressivo sobre a acumulação e distribuição de matéria seca e nutrientes em relação à idade da planta, foi realizado por SAYRE (1948), que estudou estes parâmetros, durante 3 ciclos da cultura, no hibrido duplo K35. As principais conclusões por ele apresentadas são: a) o crescimento do milho é função linear do tempo; b) a curva do peso da matéria seca da planta inteira é ligeiramente sigmóide; c) a acumulação do nitrogênio cresce nos tecidos verdes, e depois há uma intensa translocação para os grãos. Aproximadamente aos três meses, cessa a absorção, cujo máximo ocorre no "embonecamento"; d) o fósforo apresenta a mesma caracteristica do nitrogênio, sendo que pode haver perda depois dos três meses; e) o potássio aumenta até os três meses, e a partir dai começa a cair, sendo que o máximo de absorção se dá três semanas após a floração.

Esse mesmo autor (SAYRE, 1955), fez uma série de estudos sobre a absorção de nutrientes pelo milho, que se tornaram clássicos.

A acumulação de matéria seca jå fora estudada por BAIR (1942), citado em NELSON (1956), que a descreve como uma curva sigmóide característica. É vagarosa após a emergência, e acelera rapidamente até os 40 a 50 dias. Nos próximos 50 a 60 dias esta taxa é uniforme, caindo durante a maturação.

Em trabalhos mais recente, ADELANA \& MILBOURN (1972), estudaram a partição da matéria seca entre as diversas partes da planta nos híbridos K75A, Anjou-210 e $\mathrm{K} 33$, verificando que a taxa de crescimento aumenta em todos os híbridos até o pendoamento (13 semanas), e nesta época, há uma abrupta queda da taxa de assimilação líquida. $O$ peso da matéria seca do colmo só atingiu o máximo 20 semanas após o plantio, sendo que no final do ciclo ele conta $48 \%, 38 \%$ e $35 \%$ do peso total da planta, respectivamente em K75A, Anjou-210 e K33.

Esse aspecto foi estudado no Brasil por KOLLER \& MUNSTOCK (1972), que observaram a taxa de acumulação de matéria seca na planta, entre o aparecimento da espiga e a maturação fisiológica, em seis híbridos comerciais; verificando que, embora os híbridos tardios acumulem matéria seca no grão por espaço de tempo, os híbridos precoces têm maior taxa de translocação dos materiais sintetizados nas folhas para os grãos, o que resulta em maior produção.

Os dados apresentados a seguir mostram a distribuição dos nutrientes no pé de milho no fim do ciclo, segundo SAYRE (1948). 


\begin{tabular}{|c|c|c|c|}
\hline \multirow{3}{*}{ Parte da planta } & \multicolumn{3}{|c|}{ Elemento } \\
\hline & $-\mathbf{N}$ & $\mathbf{P}$ & K \\
\hline & \multicolumn{3}{|c|}{$(\mathrm{kg} / \mathrm{ha})$} \\
\hline Colmo & 20 & 5 & 40 \\
\hline Folhas & 25 & 3 & 25 \\
\hline Palha & 5 & 1 & 10 \\
\hline Grãos & 90 & 20 & 20 \\
\hline Sabugo & 5 & 1 & 5 \\
\hline TOTAL & 145 & 30 & 100 \\
\hline
\end{tabular}

Para o milho bem adubado, a colheita das espigas, corresponde aproximadamente à metade do peso da planta toda. Isto foi mostrado por ROBERTSON et al. (1968), que ainda demonstraram a correlação entre a absorção de nutrientes e a produção de grãos. Para o nitrogênio, esta relação é cerca de $2,27 \times 10^{-2}$ ( $\mathrm{kg}$ de N/ $\mathrm{kg}$ de grãos), para o fósforo, $5,0 \times 10^{-3}$, e para o potássio, $1,85 \times 10^{-2}$, o que indica que, para produzir 10 toneladas de grãos por ha, o milho necessitará de $227 \mathrm{~kg}$ de $\mathrm{N}, 50 \mathrm{~kg}$ de $\mathrm{P}$ e $185 \mathrm{~kg}$ de $\mathrm{K}$.

BRADFORD et al. (1966), estudaram a interação híbrido $\mathrm{x}$ adubação, verificando que esta não é significativa para o peso de matéria seca. $O$ tratamento com calcário dolomítico aumentou a quantidade de $\mathrm{Mg}$ acumulada por todos os híbridos, de forma idêntica.

HANWAY \& RUSSEL (1969), estudaram a acumulação de matéria seca em 11 hibridos, nos sucessivos estágios de crescimento, verificando que não havia diferenças significativas até o aparecimento da 10ạ folha. A partir dai, a taxa de crescimento é diferente, e em determinados híbridos a inflorescência feminina aparece mais cedo. Neste mesmo estudo, verificaram que o efeito do aumento da população na produção de grãos é diferente para os híbridos, variando de $-810 \mathrm{a}+1720 \mathrm{~kg} / \mathrm{ha}$.

Um trabalho interessante foi desenvolvido por LOUÉ (1963), que comparou as exigências de $\mathrm{N}, \mathrm{P}, \mathrm{K}$ em ensaios adubação $\mathrm{x}$ variedade. As suas conclusões principais foram: a) as diferenças de acumulação entre variedades começam a aparecer desde a época de formação da panícula; b) a alimentação hídrica tem papel mais importante no aumento de produção que os nutrientes sozinhos; c) os hibridos mais produtivos apresentam evapotranspiração de 15 a $25 \%$ maior que os menos produtivos; d) as diferenças entre híbridos no conteúdo de nutrientes é menor que entre ensaios, para o $\mathrm{N}$ e $\mathrm{P}$, enquanto para o K esta diferença é mais ou menos a mesma; isto é, o local tem maior influência que o cultivar; e) as variedades mais produtivas apresentam maior exigência em nutrientes minerais, pois o aumento de produção é baseado em uma maior acumulação de substâncias orgânicas nas partes vegetativas, que por sua vez está relacionado com a disponibilidade de nutrientes.

O modo e época de aplicação do nitrogênio tem influência na marcha de absorção deste nutriente, na acumulação de matéria seca nas partes vegetativas e, principalmente, nos grãos. A aplicação tardia deste nutriente aumenta o tempo de enchimento do grão, mas, provavelmente diminui a área foliar, dando uma menor taxa de acumulação relativa (NEPTUNE, 1966). 
Pelo observado, hả realmente diferenças nas características fisiológicas das linhagens puras. Entre estas, as diferenças na absorção dágua e nutrientes, têm importância fundamental para o melhoramento genético deste cereal.

$O$ presente trabalho tem a finalidade de aquilatar diferenças na acumulação dos macronutrientes e outros parâmetros vinculados, entre os cultivares: Agroceres 256, Agro ceres 504, Centralmex, H-7974 e Piranão.

\section{MATERI AL E MÉTODOS}

Foram utilizados os seguintes cultivares de milho (Zea mays L.): Agroceres 256, Agroceres 504, Centralmex, H-7974 e Piranão. O experimento foi conduzido no Município de Piracicaba, num solo classificado como Regossol, série Sertãozinho (RAN. ZANI, 1956), de média fertilidade, exceto em relação ao teor de K que é baixo.

Foram seguidas as práticas culturais comuns e a adubação consistiu de $83 \mathrm{~g}$ da fórmula 30-120-70, por metro linear no plantio, e $33 \mathrm{~g} /$ metro linear da fórmula 50-0-40, em cobertura, 22 dias após germinação.

A população de plantas foi de 50.000 por hectare.

Plantas foram coletadas a partir dos 20 dias após a germinação, em intervalos de 20 dias, até aos 120 dias. As plantas colhidas foram divididas em "colmo + folhas", pendão e espiga, e analisadas quimicamente para $\mathrm{N}, \mathrm{P}, \mathrm{K}, \mathrm{Ca}, \mathrm{Mg}$ e $\mathrm{S}$ seguidos os métodos descritos em SARRUGE \& HAAG (1974).

\section{RESULTADOS E DISCUSSÃO}

\section{Crescimento}

Os dados sobre o crescimento das plantas, expresso pela acumulação de matéria seca nos cultivares, acham-se no Quadro 1. Para uma melhor visualização foi tambe̊m estimada a produção de matéria seca $\mathrm{em} \mathrm{kg} / \mathrm{ha}$.

Pelos valores de $\mathrm{F}$ em cada época de amostragem, verificou-se diferenças significativas entre cultivares, ao nivel de $5 \%$ de probabilidade, apenas em determinadas épocas e órgãos. Aos 40, 80 e 100 dias observou-se diferenças na quantidade de matéria seca na parte vegetativa "colmo + folhas", e aos 100 e 120 dias para os pendões. Para as espigas não houve diferença significativa.

Apesar das diferenças encontradas na parte vegetativa, estas não tiveram tendência a se refletir no peso total da planta, indicando que as diferenças entre os cultivares, provavelmente se deveram ao estádio vegetativo destes, o que provocou diferenças na partição da matéria seca; e não a diferenças absolutas entre elas. 


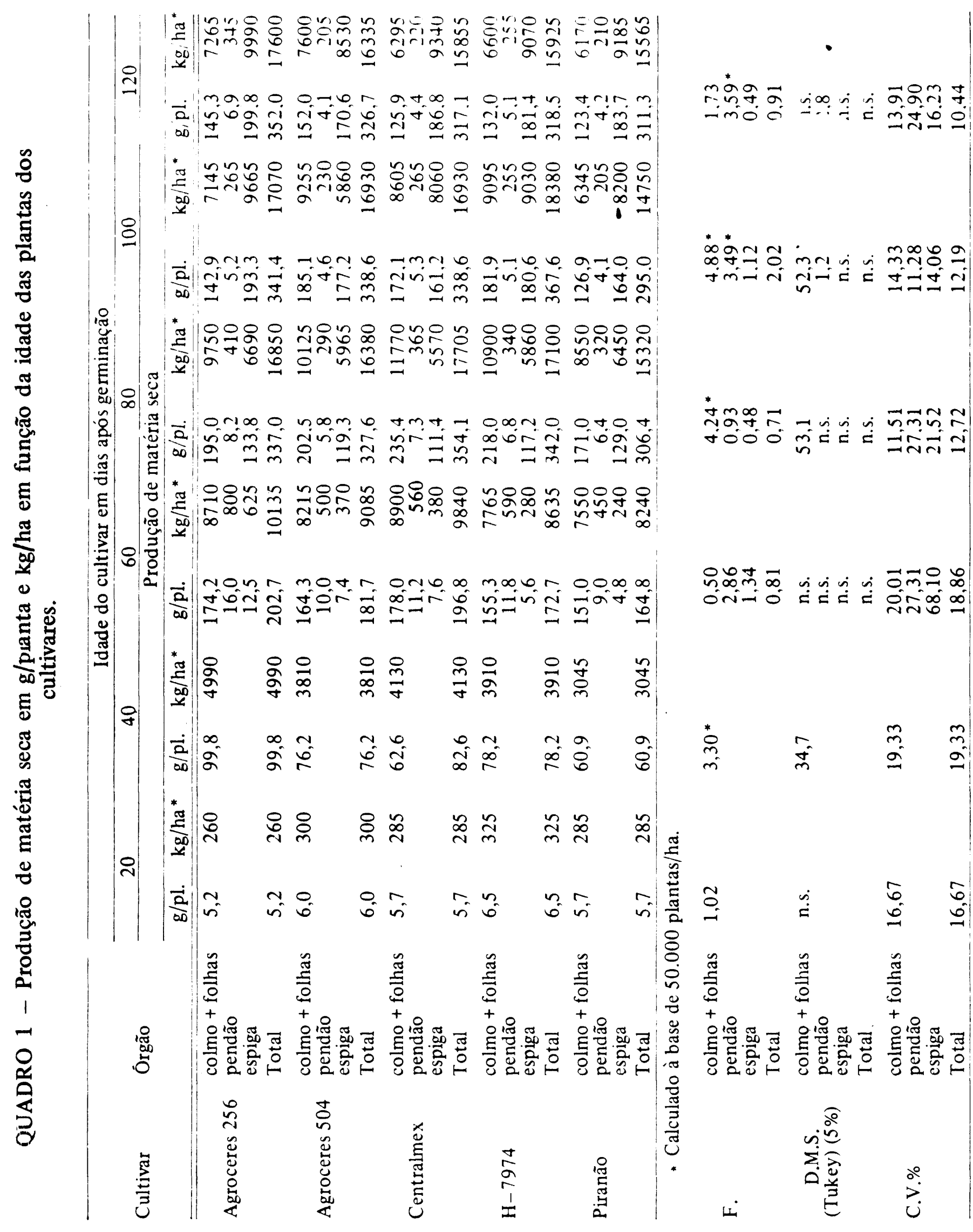




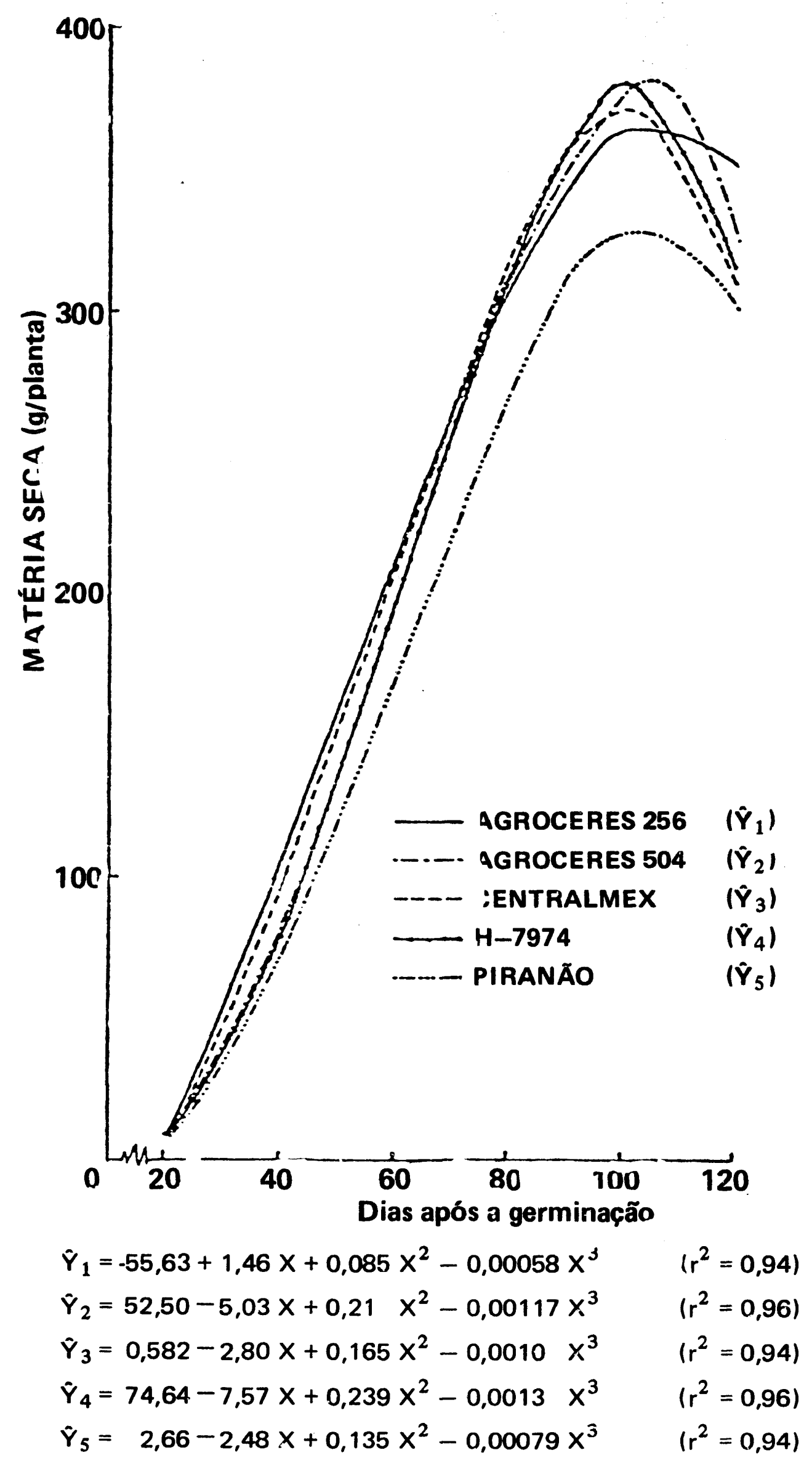

Figura 1 - Curvas de regressão da quantidade de matéria seca $(\widehat{Y})$ em função da idade $(X)$ nos cultivares. 
A expressão matemática do crescimento foi obtida através da análise de regressão. A escolha da curva recaiu sobre aquela de maior grau, até o 4 ọ grau, cujo componente mais elevado foi significativo. As curvas correspondentes constam da Figura 1, na qual se observa que o crescimento dos cultivares utilizados obedeceu equações do 30 grau.

Para estimar o ponto em que, teoricamente, os cultivares apresentaram uma quantiJade máxima de matéria seca (Ponto de Máximo), foram obtidas as raizes da equação diferencial de 1ạ ordem. Este valor, substituido na equação principal, deu o valor má ximo calculado de matéria seca por planta.

O ponto de inflexão, isto é, a idade em que, teoricamente, a taxa de acumulação é máxima, foi obtido pela resolução da diferencial de 2 ạ ordem (somente para as equações de 30 e e 4 ̣ graus). Esses dados são apresentados a seguir:

\begin{tabular}{lccc}
\hline Zultivar & $\begin{array}{c}\text { Ponto de máximo } \\
\text { (dias) }\end{array}$ & $\begin{array}{c}\text { Quantidade máxima } \\
\text { (g/planta) }\end{array}$ & $\begin{array}{c}\text { Ponto de inflexão } \\
\text { (dias) }\end{array}$ \\
\hline \hline tgroceres 256 & 106 & 363,4 & 49 \\
Agroceres 504 & 103 & 380,8 & 60 \\
Centralmex & 101 & 370,6 & 55 \\
H-7974 & 100 & 381,0 & 60 \\
Piranão & 105 & 327,0 & 57 \\
\hline
\end{tabular}

Como se nota na Figura 1, a partir dos 40 dias os milhos de porte normal tiveram uma maior taxa de acumulação de matéria seca que o Piranão, e a quantidade máxima naqueles foi ligeiramente maior. Contudo, a diferença residiu na parte vegetativa, provavelmente devido à diminuição dos internódios causada pelo gene braquitico (PATERNIANI, 1973), o que provocaria uma diminuição da quantidade de matéria seca no zolmo.

O cultivar Agroceres 256 atingiu o seu ponto de inflexão mais cedo que os outros, $\checkmark$ que indica precocidade, embora o seu ponto de máximo fosse o mais tardio.

Como citam, SAYRE (1948), NELSON (1956) e HANWAY (1962a), a acumulação de matéria seca na planta de milho segue uma curva sigmóide, sendo que entre os $40 \mathrm{e}$ 100 dias ela é linear. No presente trabalho, verificou-se um acúmulo de cerca de 250 a $300 \mathrm{~kg} / \mathrm{ha}$ de matéria seca por dia durante esta fase.

SAYRE $(1948,1955)$ e HANWAY (1962a), mostraram que a quantidade máxima de matéria seca deve ocorrer na maturação fisiológica. Após esta época se indica a degenerescência dos tecidos da planta. Assumindo que esta assertiva é verdadeira, os cultivares estudados devem ter sua maturação fisiológica completada em torno dos 110 dias após a emergência. Após esta idade, começou a decrescer o peso total da planta, provavelmente devido a queda de folhas senescentes, fenômeno também observado por LOUÉ (1963), em ensaio não irrigado. Para contornar este problema, HANWAY (1962a), considerou como peso da matéria seca aos 120 dias, aquela apresentado aos 100, acrescido da diferença no peso dos grãos aos 120 de 100 dias.

O resultado obtido no presente ensaio concorda, dentro dos limites impostos pelas condições de solo, adubação, clima e cultivares empregados, com os apresentados por 
SAYRE (1948, 1955); HANWAY (1962a); LOUÉ (1963); NEPTUNE (1966); BRADFORD it al. (1966); KOLLER \& MUNSTOCK (1972); ADELANA \& MILBOURN (1972), valendo salientar, que a irregularidade da precipitação durante o ciclo vegetativo, deve ter influido no comportamento das plantas, pois este é um dos principais fatores envolvidos na produção de matéria seca (VIETS, 1962; HANWAY, 1967).

De um modo geral, dentro das limitaçбes impostas pelas condiçōes, pode-se afirmar que cultivares com produções semelhantes, como neste caso, devem acumular matéria seca em quantidades similares, embora os milhos de porte anão tenham tendência a apresentar uma maior relação grão/matéria seca total. Isto também foi verificado, para os cultivares de porte normal: Centralmex, HV e H-6999-b, por BARRIGA BEZANILLA (1971), e para o Piranão por LEITE \& PATERNIANI (1973); também, ROBERTSON et al. (1968), observaram que a relação grão/matéria seca total varia com o híbrido, e com as condições de clima de fertilização.

\section{Acumulação de macronutrientes}

Os resultados obtidos relativos a percentagem e quantidade de macronutrientes nos cinco cultivares estão contidos nos Quadros 2 a 7.

Pode-se afirmar que, de um modo geral, a quantidade e percentagem desses nutrientes abrange a faixa observada para outros cultivares já pesquisados.

Para o N, P e K, praticamente só encontrou-se diferenças entre cultivares aos 40 dias. Nesta época, os cultivares que apresentavam maior quantidade de matéria seca, também possuiam maior quantidade destes nutrientes. Este comportamento é normal, porquarto vários pesquisadores já mostraram que, a não ser em casos específicos, a produção de matéria seca depende, em grande parte, da quantidade de nutrientes presentes, especialmente N, P e K (HANWAY, 1962a; ASHBURN, 1971; PEASLEE et al., 1971; DYNARD et al., 1971; VOSE, 1963).

Os cultivares atingiram o máximo da quantidade de $\mathrm{P}$ ao mesmo tempo que o de matéria seca, quando deve ter ocorrido a maturação fisiológica. $\mathrm{O}$ máximo de $\mathrm{N}$, cerca de 6 a 8 dias antes, e o máximo de $\mathrm{K}$, em torno da época do pendoamento.

Durante o amadurecimento dos órgãos vegetativos houve perda considerável do $\mathrm{K}$, provavelmente devido à lavagem do ion e degenerescência de células e tecidos (SAYRE, 1955; LOUÉ, 1963; PESEK, 1968; LIEBHARDT, 1968; EPSTEIN, 1972; MALAVOLTA et al., 1974).

Os macronutrientes absorvidos predominantemente como cátions ou ânions divalentes, apresentaram maiores diferenças de acumulação entre cultivares, sendo que estas diferenças só se manifestaram após o pendoamento, na época de maior acumulação destes nutrientes.

Verificou-se que os cultivares estudados diferiram em relação a absorção de $\mathrm{Ca}$, $\mathrm{Mg}$ e $\mathrm{S}$, bem como, nas relações $\mathrm{Ca}+\mathrm{Nig} / \mathrm{K}$ e $\mathrm{Ca}+\mathrm{Mg} / \mathrm{S}$; fatos para os quais já foi demonstrada a ação do controle genético (GORSLINE et al., 1961; BAKER et al., 1966; BAKER et al., 1967; VOSE, 1963; JENNE et al., 1958; BARBER, 1968; MENGEL, 1968; GORSLINE et al., 1964; BRADFORD et al., 1966; NELSON, 1968). 
Comparando-se o cultivar Agroceres 504 (opaco-2) com os demais, verificou-se que o mesmo absorveu menos $\mathrm{Ca}$ e $\mathrm{Mg}$ e mais $\mathrm{S}$ que aqueles, fato este que deve ser melhor estudado. Não se pode afirmar que o gene $\mathrm{O}_{2}$ acarretou este comportamento, devido à falta de informações sobre o assunto.

Do mesmo modo que a produção de grãos varia bastante entre plantas individualmente (DUNCAN, 1967), a absorção de macronutrientes também sofre variações acentuadas. Assim, é provável que o número de amostras tenha sido muito reduzido para estabelecer diferenças, porventura existentes entre cultivares.

As diferenças de acumulação de macronutrientes entre cultivares se restringiram, em sua maior parte, à parte vegetativa, mostrando que, pelo menos em parte, deve estar associada ao sistema de distribuição dos nutrientes na planta (EPSTEIN \& JEFFERIES, 1964; EPSTEIN, 1972; FERRARI \& RENOSTO, 1972).

\section{Nitrogênio}

Os dados analíticos referentes à acumulação e percentagem de nitrogênio nos cultivares acham-se no Quadro 2. O teste de $\mathrm{F}$ mostrou diferenças significativas entre cultivares, em relação à parte vegetativa, aos 40 e 60 dias. Os pendões e espigas não apresentaram diferenças.

Pela comparação das médias aos 40 dias, verificou-se que as diferenças observadas, são entre os cultivares Agroceres 256 e Piranão. O primeiro, além da maior quantidade de matéria seca também apresentou maior percentagem de $\mathrm{N}$, o que resultou em maior quantidade de $\mathrm{N}$ na planta.

A análise da regressão mostrou que a acumulação de $\mathrm{N}$ nos cultivares pode ser calculada por equações do 20 grau. Isto indica que não há aceleração da acumulação até um ponto de inflexão, como no caso da matéria seca. As curvas e as equações corres: pondentes acham-se na Figura 2. Os coeficientes de determinação das curvas $\left(\mathrm{r}^{2}\right)$, em. bora sejam altos, são menores que os observados para a matéria seca.

Os pontos de máximo calculados e as quantidades máximas para cada cultivar, são apresentados a seguir:

\begin{tabular}{lcc}
\hline Cultivar & $\begin{array}{c}\text { Ponto de máximo } \\
\text { (dias) }\end{array}$ & $\begin{array}{c}\text { Quantidade máxima } \\
\text { (mg/planta) }\end{array}$ \\
\hline \hline Agroceres 256 & 95 & 3878 \\
Agroceres 504 & 100 & 3507 \\
Centralmex & 89 & 3354 \\
H-7974 & 92 & 3526 \\
Piranão & 96 & 3169 \\
\hline
\end{tabular}




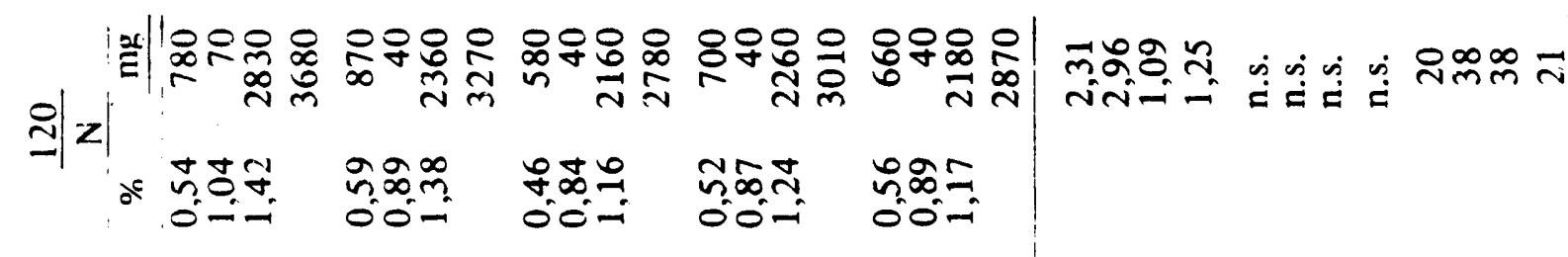

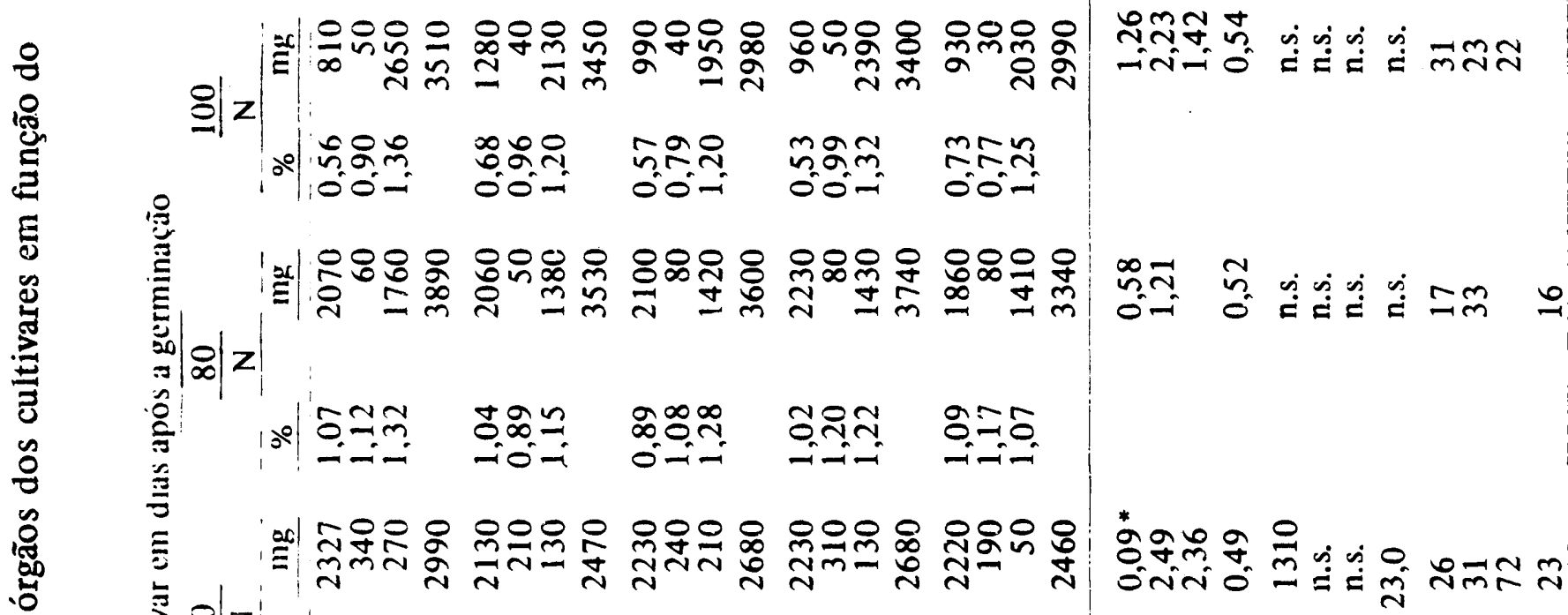

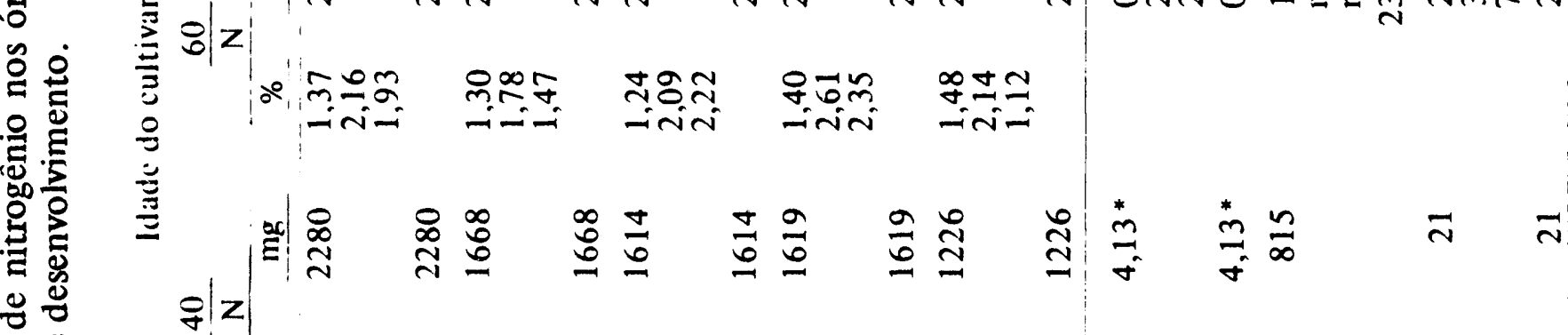

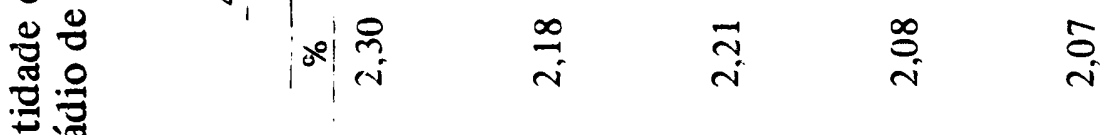

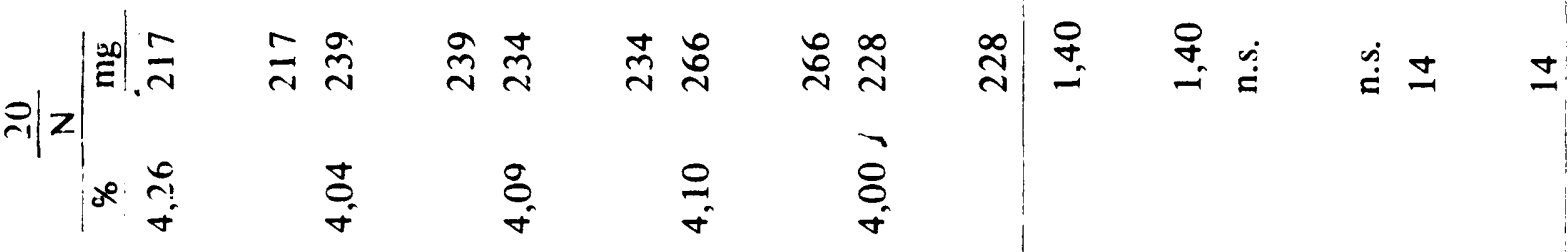

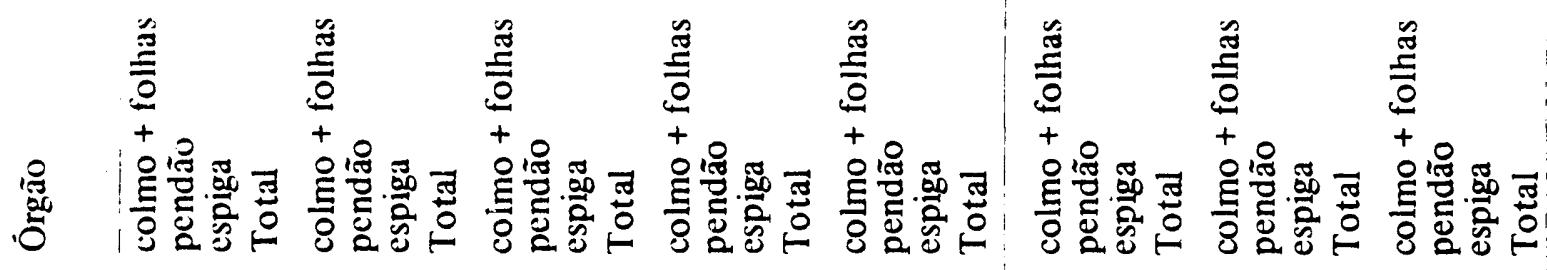

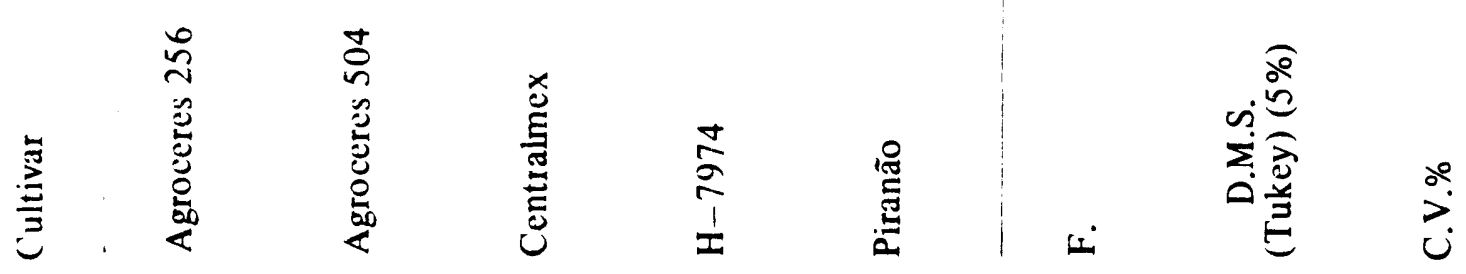




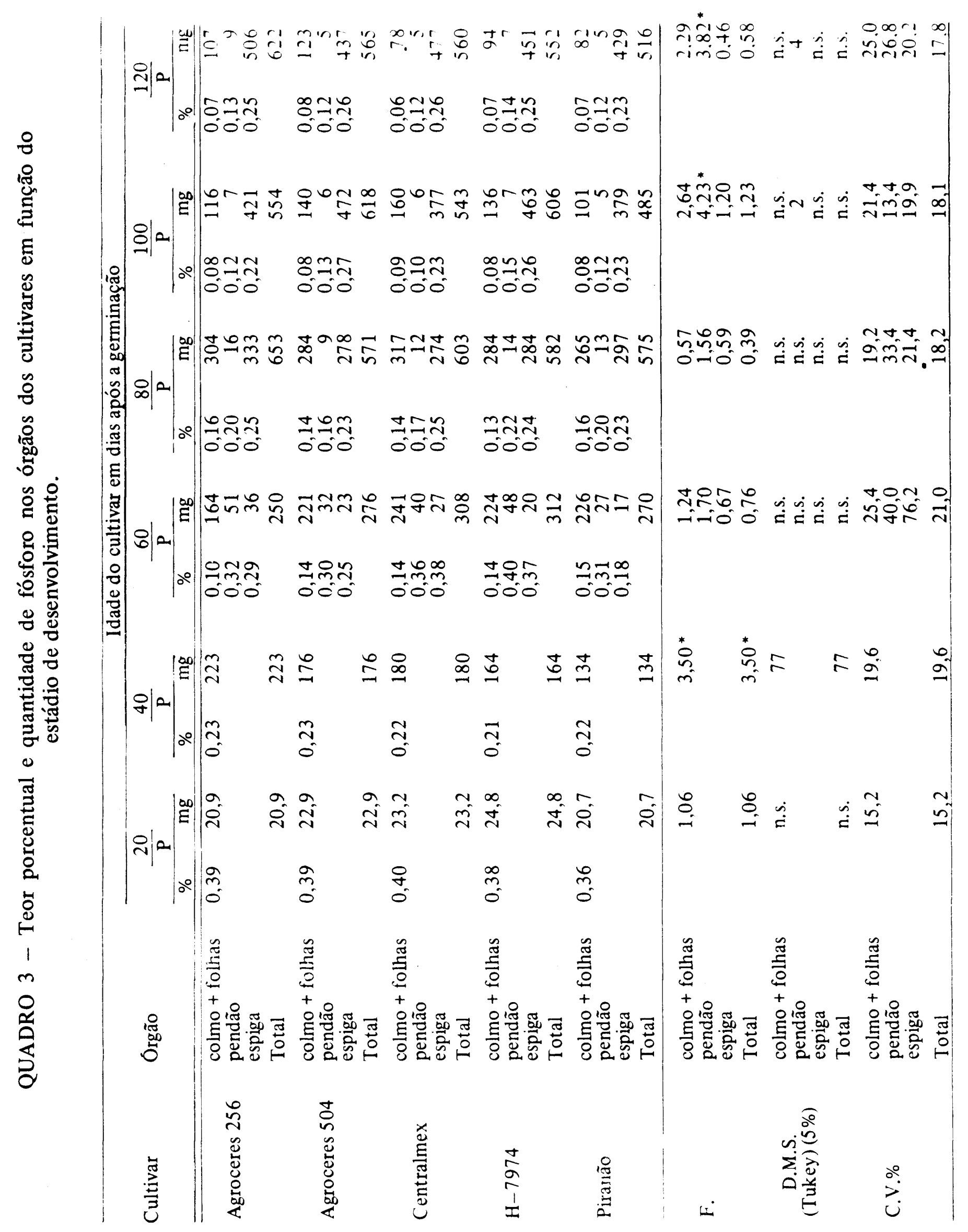




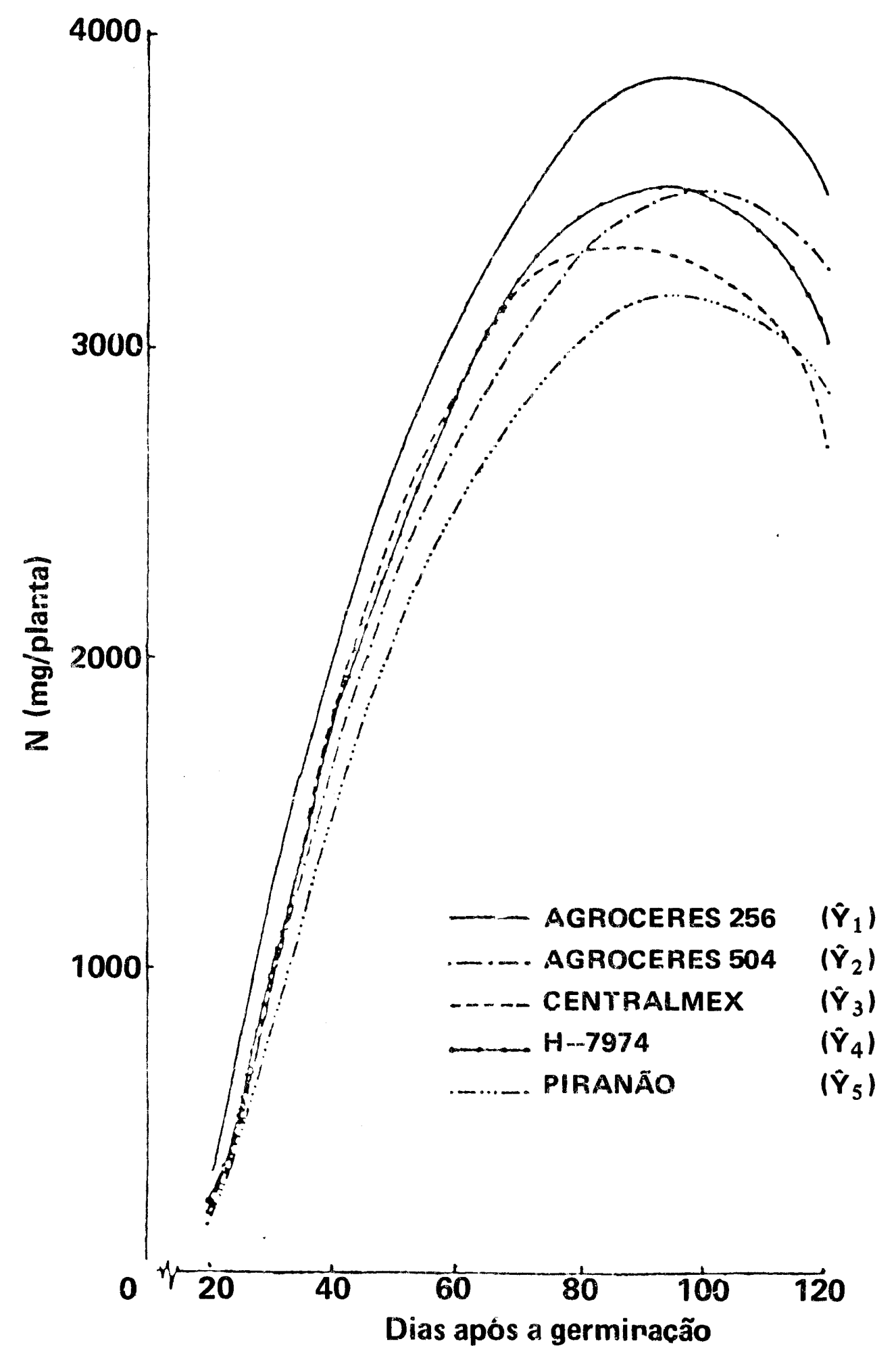

$$
\begin{array}{ll}
\hat{Y}_{1}=-1.730,57+117,56 X-0,616 X^{2} & \left(r^{-}=0,83\right) \\
\hat{Y}_{2}=-1.653,57+103,41 X-0,518 X^{2} & \left(r^{2}=0,88\right) \\
\hat{Y}_{3}=-1.840,5+117,29 X-0,662 X^{2} & \left(r^{2}=0,86\right) \\
\hat{Y}_{4}=-1.947,77+118,29 X-0,639 X^{2} & \left(r^{2}=0,85\right) \\
\hat{Y}_{5}=-1.727,42+102,27 X-0,534 X^{2} & \left(r^{2}=0,87\right)
\end{array}
$$

Figura 2 - Curvas de regressão da quantidade de nitrogênio $(\widehat{Y})$ em função da idade $(X)$ nos cultivares. 
Pela análise destes dados e dos apresentados na Tabela 2, verificou-se que o cultivar Agroceres 256 apresentou uma quantidade de $\mathrm{N}$ cerca de $700 \mathrm{mg}$ por planta maior que o Piranão, o que corresponderia a $35 \mathrm{~kg} / \mathrm{ha}$. Contudo, a não significância dessa diferença, sem como, o valor relativamente alto do coeficiente de variação, mostraram que as difeenças entre individuos fo elevada. Quanto ao decréscimo verificado na quantidade total de $\mathrm{N}$ no fim do ciclo, é provável que a mesma explicação aventada para a matéria seca seja válida para o $\mathrm{N}$.

SAYRE (1955), HANWAY (1962b) e LOUÉ (1963), encontraram que o máximo de $\mathrm{N}$ ocorre em torno dos 90-100 dias, no que concordou o presente ensaio. Uma quantidade máxima de $144 \mathrm{lb} /$ acre, foi encontrada por SAYRE (1948), o que corresponde a $161 \mathrm{~kg} / \mathrm{ha}$. LOUÉ (1963), encontrou $110 \mathrm{~kg} / \mathrm{ha}$ e $194 \mathrm{~kg} / \mathrm{ha}$, respectivamente, para o ensaio não irrigado e irrigado, o que dá $2.750 \mathrm{mg}$ e $4.850 \mathrm{mg} /$ planta. Os resultados encontrados no presente ensaio situaram-se dentro desses limites.

\section{Fósforo}

Os dados analíticos referentes à quantidade e percentagem de $\mathrm{P}$ nos cultivares acham-se no Quadro 3. Pelos valores de $F$ na análise de variância observou-se que só houve diferenças entre cultivares aos 40 dias, e nos pendões aos 100 e 120 dias.

Confrontando-se os dados dos Quadros 1 e 3, constatou-se que esta diferença aos 40 dias deve ser devida à quantidade de matéria seca, pois as percentagens de $\mathrm{P}$ nos diferentes cultivares foram essencialmente iguais.

A análise de regressão mostrou que a acumulação no cultivar Agroceres $256 \mathrm{se}$ guiu uma curva do 29 grau, enquanto nos outros foram significativos os componentes até o 30 grau. As curvas e equações acham-se na Figura 3.

Como se pode verificar, a curva de acumulação de $\mathrm{P}$ é semelhante à da matéria seca, embora o cultivar Agroceres 256 tenha divergido um pouco. Este cultivar absorveu $P$ até os 120 dias, enquanto nos outros o ponto de máximo foi bastante próximo daquele para a matéria seca. Estes dados, e a quantidade máxima calculada, são apresentados a seguir:

\begin{tabular}{lccc}
\hline Cultivar & $\begin{array}{c}\text { Ponto de máximo } \\
\text { (d1as) }\end{array}$ & $\begin{array}{c}\text { Quantidade máxima } \\
\text { (mg/planta) }\end{array}$ & $\begin{array}{c}\text { Ponto de inflexão } \\
\text { (dias) }\end{array}$ \\
\hline \hline Agroceres 256 & 120 & 625,5 & - \\
Agroceres 504 & 104 & 641,8 & 60 \\
Centralmex & 104 & 614,5 & 52 \\
H-7974 & 103 & 642,3 & 58 \\
Piranão & 101 & 541,2 & 55 \\
\hline
\end{tabular}




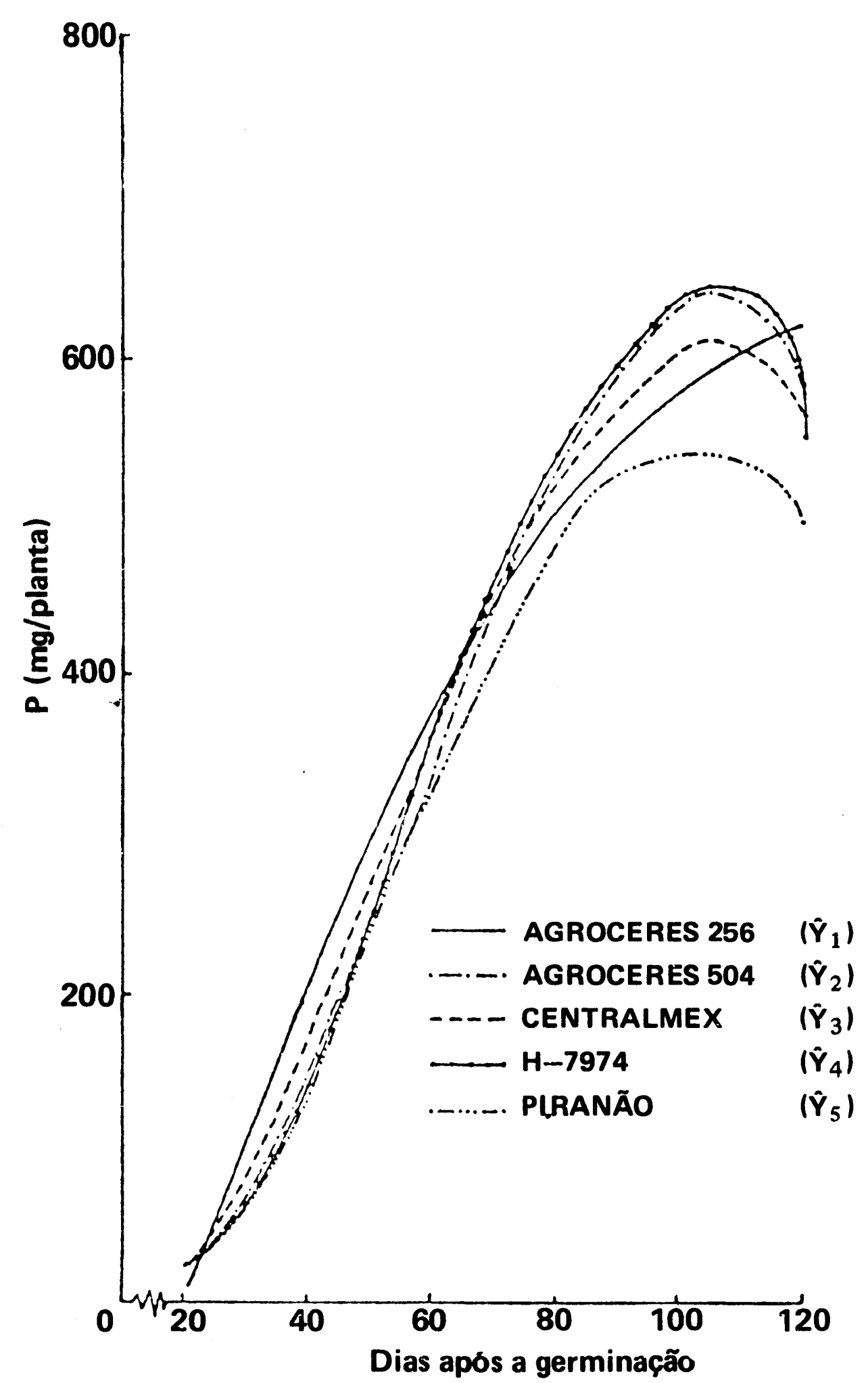

$$
\begin{array}{lll}
\hat{Y}_{1}=-240,50+13,337 x-0,051 X^{2} & \left(r^{2}=0,80\right) \\
\hat{Y}_{2}=96,12-8,98 x+0,324 X^{2}-0,0018 X^{3} & \left(r^{2}=0,89\right) \\
\hat{Y}_{3}=-36,20-0,42 x+0,189 X^{2}-0,0012 x^{3} & \left(r^{2}=0,90\right) \\
\hat{Y}_{4}=71,79-7,81 X+0,315 X^{2}-0,0018 X^{3} & \left(r^{2}=0,92\right) \\
\hat{Y}_{5}=10,87-3,90 x+0,232 X^{2}-0,0014 X^{3} & \left(r^{2}=0,84\right)
\end{array}
$$

Figura 3 - Curvas de regressão da quantidade de fósforo $(\hat{Y})$ em fụnção da idade $(\mathrm{X})$ nos cultivares. 
Como se nota, o ponto de exigência máxima situou-se próximo da época do pendoamento, que ocorreu em torno dos 60 dias após a germinação.

Comparando-se a quantidade de $\mathrm{P}$ absorvida pelos cultivares, com a apresentada por outros autores, SAYRE (1948, 1955); HANWAY (1962b); LOUE (1963); NEPTUNE (1966), ela foi semelhante desde que se faça a comparação em termos de idade fisiológica. Contudo, foi maior que a encontrada por JONES \& HUSTON (1914), mostrando que, em relação aos cultivares empregados no início do século, os atuais devem ser mais exigente e ter maior capacidade de absorção de $P$.

\section{Potássio}

Os dados analíticos referentes à quantidade de $\mathrm{K}$ acumulada e percentagem deste nutriente nos órgãos dos cultivares acham-se no Quadro 4.

Como se nota, a única diferença significativa pelo teste de $\mathrm{F}$ foi, aos 40 dias, entre os cultivares Agroceres 256 e Piranão.

Todos os cultivares acumulam $\mathrm{K}$ seguindo equaçб̃es do 30 grau, conforme mostra a Figura 4.

A quantidade máxima de $\mathrm{K}$ ocorreu bem antes que a de $\mathrm{N}$ e $\mathrm{P}$, e no ponto máximo, os cultivares Agroceres 256 e 504 tinham cerca de $600 \mathrm{mg} /$ planta a mais que os outros, embora esta diferença entre médias não atingisse o limite da significância. Além disso, 0 ponto de inflexão encontrado se refere ao processo de perda de potássio e não a acumulação. Isto quer dizer, que a taxa de acumulação de $\mathrm{K}$ é máxima no início do ciclo, e que durante a perda de $K$ pelas plantas, após uma fase em que a perda é máxima, tende a se anular. Estes dados são apresentados a seguir:

\begin{tabular}{lccc}
\hline Cultivar & $\begin{array}{c}\text { Ponto de máximo } \\
\text { (dias) }\end{array}$ & $\begin{array}{c}\text { Quantidade máxima } \\
\text { (mg/planta) }\end{array}$ & $\begin{array}{c}\text { Ponto de inflexão } \\
\text { (dias) }\end{array}$ \\
\hline \hline Agroceres 256 & 58 & 4693 & 88 \\
Agroceres 504 & 64 & 4630 & 99 \\
Centralmex & 61 & 4098 & 94 \\
H-7974 & 62 & 4064 & 94 \\
Piranão & 66 & 3850 & 113 \\
\hline
\end{tabular}

No final do ciclo, os cultivares apresentavam cerca de metade da quantidade máxima extraida.

Embora os dados obtidos não fossem suficientes para se verificar contrastes, houve concordância de LOUÉ (1963), em que, cultivares com potencial de produção semelhantes devem acumular quantidades similares de $\mathrm{K}$.

É provável que nossa adubação potássica tenha sido elevada, pois os resultados en. contrados são bem maiores que os apresentados por SAYRE $(1948,1955)$; NELSON (1956); LOUÉ (1963); MALAVOLTA et al. (1974). 


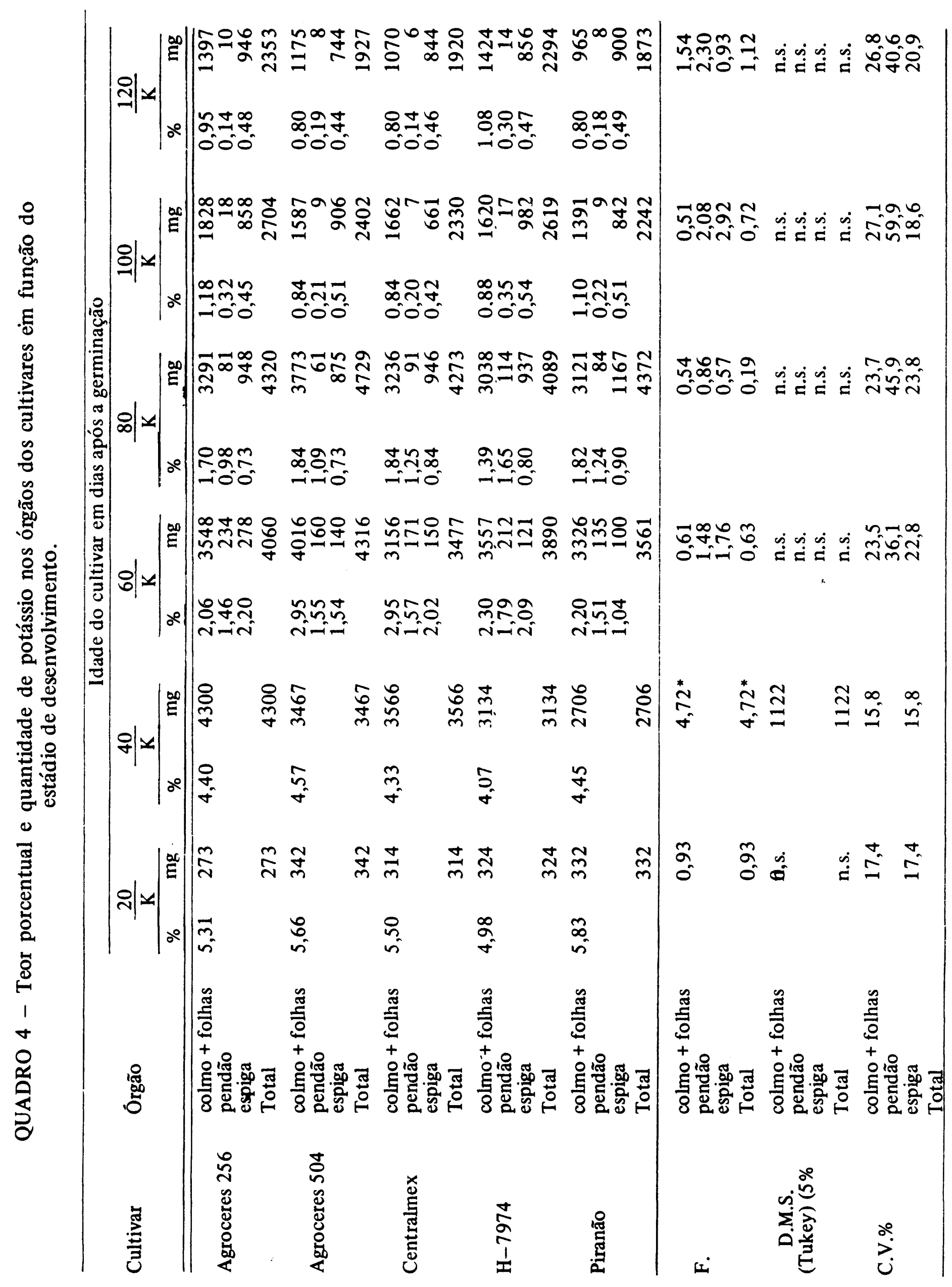




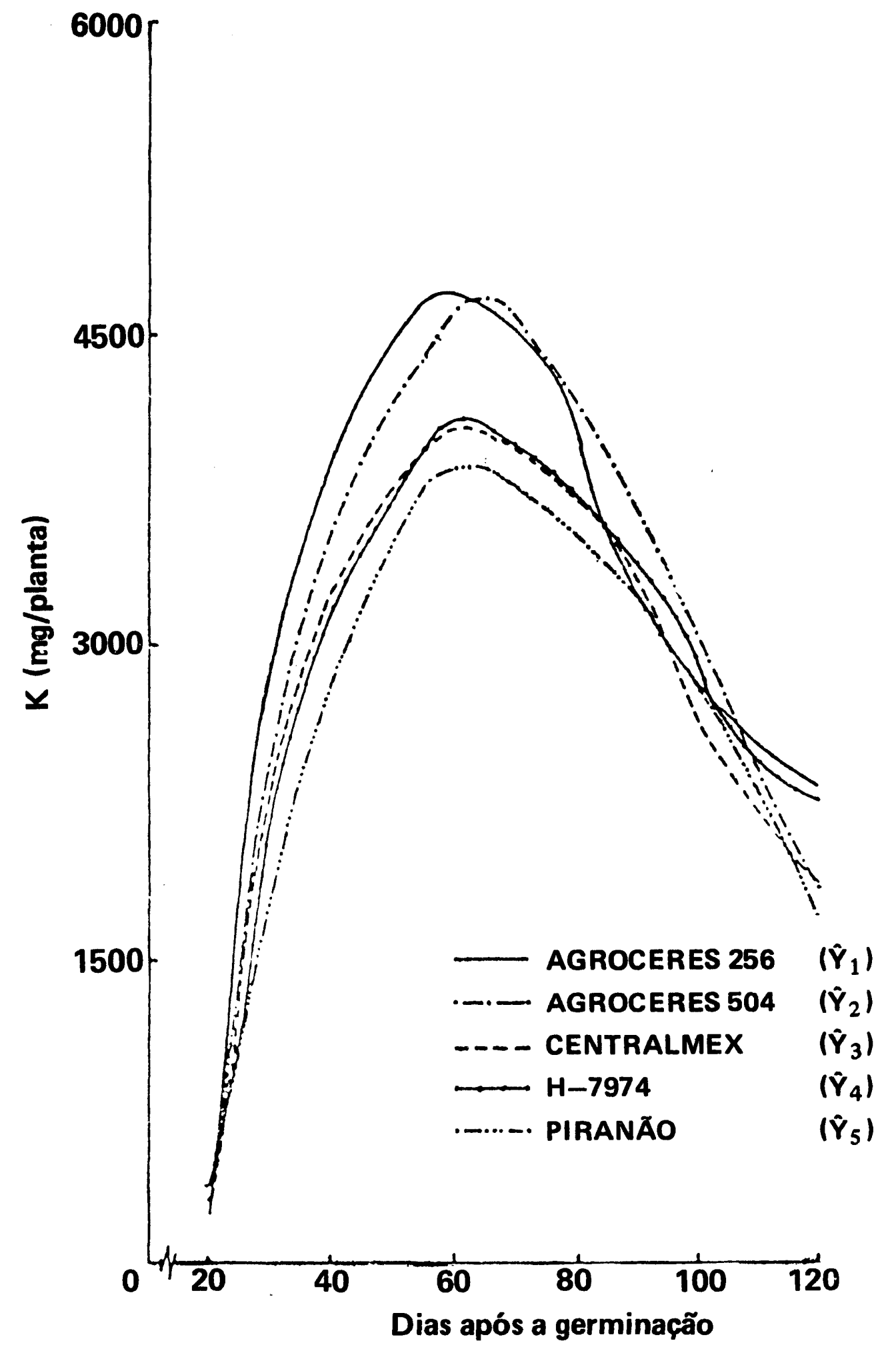

$\begin{array}{ll}\hat{Y}_{1}=-6.942,71+480,97 X-6,214 X^{2}+0,0238 X^{3} & \left(r^{2}=0,82\right) \\ \hat{Y}_{2}=-5.780,99+387,64 X-4,475 X^{2}+0,015 X^{3} & \left(r^{2}=0,76\right) \\ \hat{Y}_{3}=-5.301,55+366,15 X-4,428 X^{2}+0,0156 X^{3} & \left(r^{2}=0,81\right) \\ \hat{Y}_{4}=-5.226,52+355,30 X-4,250 X^{2}+0,0151 X^{3} & \left(r^{2}=0,82\right) \\ \hat{Y}_{5}=-4.275,19+283,86 X-3,023 X^{2}+0,0089 X^{3} & \left(r^{2}=0,81\right)\end{array}$

Figura 4 - Curvas de regressão da quantidade de potássio $(\widehat{Y})$ em função da idade $(\mathrm{X})$ nos cultivares. 


\section{Cálcio}

Os dados referentes à acumulação e percentagem de $\mathrm{Ca}$ nos diferentes cultivares acham-se no Quadro 5.

Pelos valores de $\mathrm{F}$ pode-se notar que só houve diferenças significativas para a parte vegetativa, ao nivel de $1 \%$, aos 80 dias. Verificou-se que o cultivar H-7974 tem, nesta época, as maiores quantidades de $\mathrm{Ca}, \mathrm{o}$ que ocorre também para o $\mathrm{Mg}$, enquanto, o Agroceres 504 tem a menor média.

Aos 100 dias as diferenças não foram mais detectadas; donde se pode inferir que estas diferenças foram apenas temporal, isto é, que a maior ou menor absorção de $\mathrm{Ca}^{++}$é função do tempo. Este fato ficou mais explícito pelos pontos de máximo calculados.

A quantidade de Ca na espiga foi diferente aos 120 dias, notando-se que a quantidade de Ca na espiga do cultivar Piranão diminuiu dos 100 aos 120 dias, enquanto nos outros aumentou.

As curvas de regressão que melhor descrevem a acumulação de Ca variaram, quanto ao grau, para os diferentes cultivares. Além disso, embora os pontos de máximo sejam diferentes, os pontos de inflexão são idênticos, o que sugere diferenças na forma da curva. As curvas e equações de regressão acham-se na Figura 5.

Pela quantidade máxima calculada, embora não se tenham feito análise estatística, indicou que o cultivar H-7974 acumula mais $\mathrm{Ca}$ que os outros, sendo que o Piranão e Agroceres 504 foram os que apresentaram menor quantidade máxima deste nutriente. Esses dados são apresentados a seguir:

\begin{tabular}{lccc}
\hline Cultivar & $\begin{array}{c}\text { Ponto de máximo } \\
\text { (dias) }\end{array}$ & $\begin{array}{c}\text { Quantidade máxima } \\
\text { (mg/planta) }\end{array}$ & $\begin{array}{c}\text { Ponto de inflexão } \\
\text { (dias) }\end{array}$ \\
\hline Agroceres 256 & 88 & 609 & - \\
Agroceres 504 & 94 & 584 & 44 \\
Centralmex & 84 & 653 & - \\
H-7974 & 78 & 782 & 45 \\
Piranão & 75 & 582 & 44 \\
\hline
\end{tabular}

No trabalho apresentado por SAYRE (1955), a quantidade máxima descrita foi cerca de $325 \mathrm{mg} /$ planta, enquanto LOUE (1963) e BENNE et al. (1964), citados em OLSON \& LUCAS (1967) encontraram quantidades superiores a $800 \mathrm{mg} / \mathrm{planta}$. No prese $_{1}{ }^{\circ}$ e estudo encontrou-se quantidades intermediárias, e a variabilidade verificada pode ser atribuída ao regime hidrico, e a amostragem.

Todos os cultivares apresentaram certa perda de $\mathrm{Ca}$, que provavelmente se deve à lixiviação, queda de folhas basais e, talvez, perda pelas raizes. 


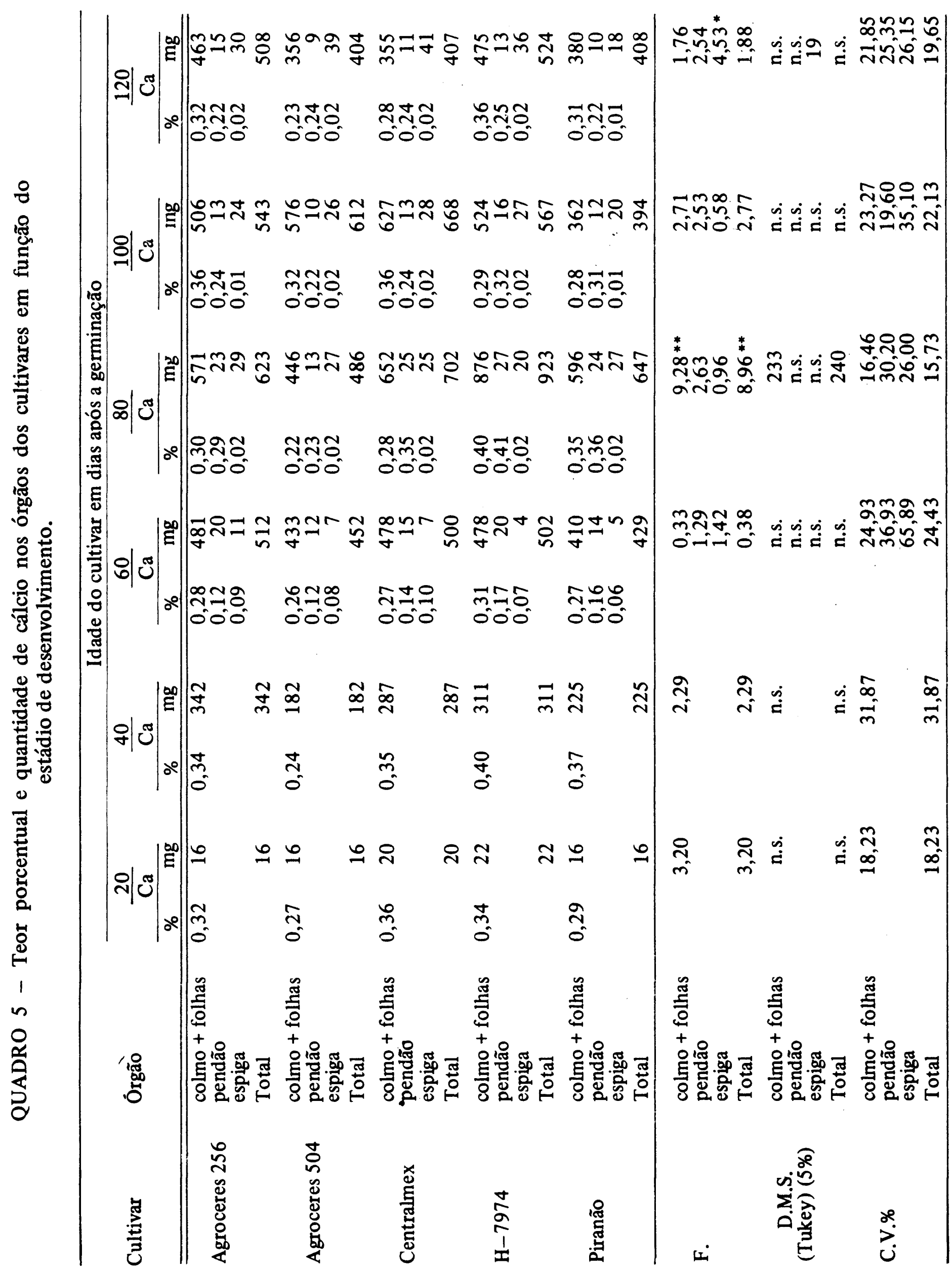




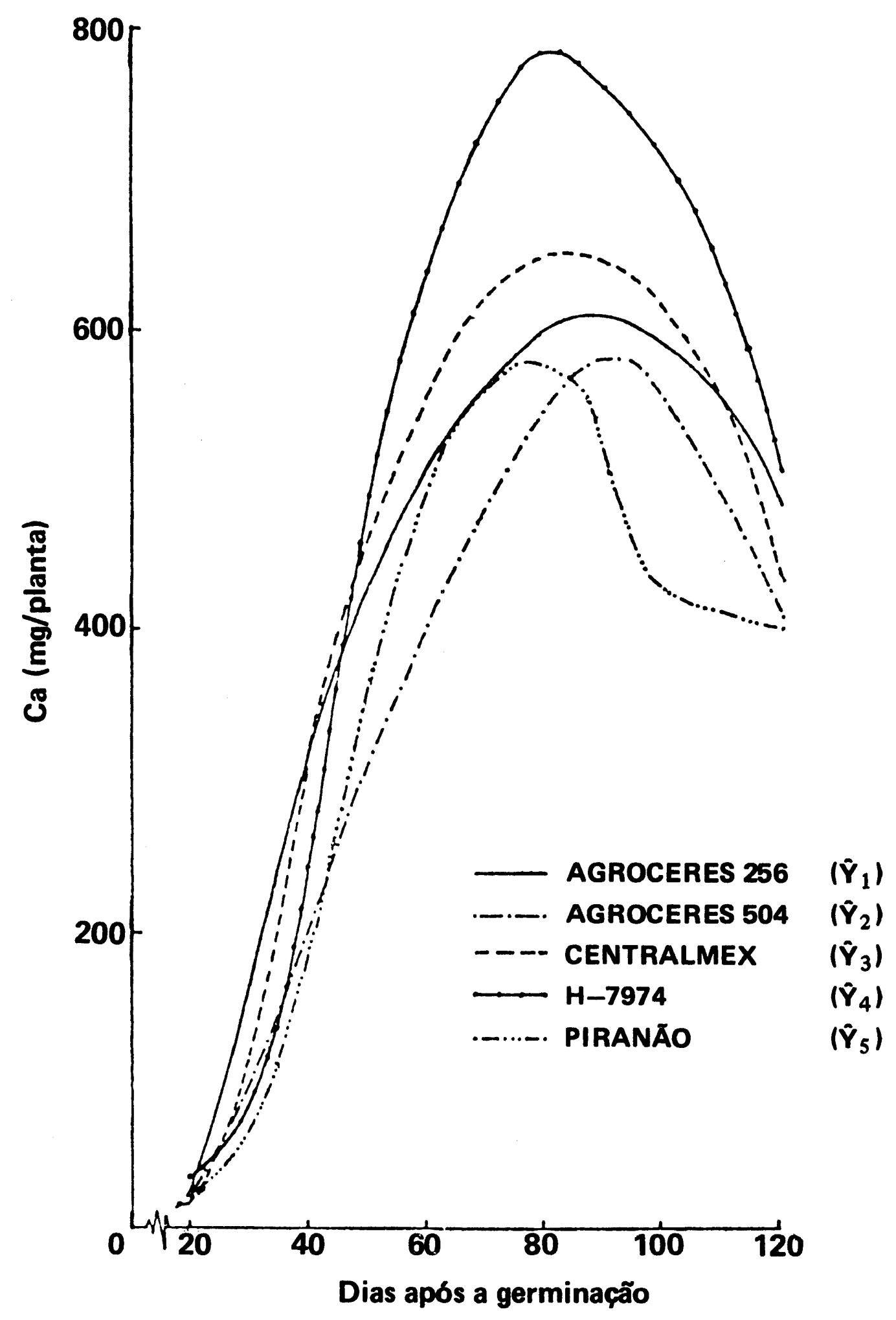

$$
\begin{array}{llll}
\hat{Y}_{1}=-365,59+22,013 X-0,1243 X^{2} & \left(r^{2}=0,87\right) & \\
\hat{Y}_{2}=-95,53+2,3308 X+0,1829 X^{2}-0,00139 & x^{3} \quad\left(r^{2}=0,89\right) & \\
\hat{Y}_{3}=-501,11+27,339 X-0,1619 x^{2} & \left(r^{2}=0,81\right) & \\
\hat{Y}_{4}=834,98-83,540 X+2,719 & x^{2}-0,029 & x^{3}+0,0000995 X^{4} & \left(r^{2}=0,79\right) \\
\hat{Y}_{5}=716,78-72,777 X+2,393 & x^{2}-0,0263 & x^{3}+0,0000935 x^{4} & \left(r^{2}=0,87\right)
\end{array}
$$

Figura 5 - Curvas de regressão da quantidade de cálcio $(\widehat{Y})$ em função da idade $(\mathrm{X})$ nos cultivares. 


\section{Magnésio}

Os dados analiticos 'referentes à quantidade e percentagem de $\mathrm{Mg}$ nos órgãos dos cultivares encontram-se no Quadro 6.

Os valores de $\mathrm{F}$ obtidos mostraram ser significativos, ao nivel de $1 \%$ de probabilidade, para a parte vegetativa aos 80 e 100 dias e para o total aos 80 dias; e ao nivel de $5 \%$, para a quantidade total aos 60 e 100 dias, e para os pendores aos 120 dias.

A diferença de comportamento entre cultivares foi evidenciada pela análise de regressão, cujas curvas acham-se na Figura 6. Verificou-se que os cultivares Agroceres 256 e Centralmex seguiram curvas do 29 grau. O Agroceres 504, seguiu uma reta (10 grau), e o H-7974 e Piranão, adaptaram-se melhor a curvas de 30 grau.

Constatou-se tambe̊m, que o H-7974 e Piranão apresentavam quantidade máxima de $\mathrm{Mg}$ aos 100 dias, enquanto os outros cultivares só a atingiram no final do ciclo. Estes dados são apresentados a seguir:

\begin{tabular}{lccc}
\hline Cultivar & $\begin{array}{c}\text { Ponto de máximo } \\
\text { (dias) }\end{array}$ & $\begin{array}{c}\text { Quantidade máxima } \\
\text { (mg/planta) }\end{array}$ & $\begin{array}{c}\text { Ponto de inflexão } \\
\text { (dias) }\end{array}$ \\
\hline \hline Agroceres 256 & 120 & 732,6 & - \\
Agroceres 504 & 120 & 785,6 & - \\
Centralmex & 120 & 654,5 & - \\
H-7974 & 100 & 942,9 & 62 \\
Piranão & 100 & 700,4 & 60 \\
\hline
\end{tabular}

CLARK \& BROWN (1974), mostraram que diferentes linhagens de milho, apresentam capacidade diferente de extração de Mg do solo. Também SAYRE (1955), já havia encontrado diferenças significativas nas concentraçбes de $\mathrm{Mg}$ nas folhas de diferentes cultivares.

Comparando-se os dados obtidos com os apresentados na literatura, verificou-se que os cultivares empregados acumulam maior quantidade de $\mathrm{Mg}$ na parte vegetativa (SAYRE, 1955; LOUÉ, 1963).

Notou-se tambẻm, que houve diferenças na distribuição do Mg na planta de milho, pois nem sempre para maior quantidade na palha houve correspondência na espiga. Fenômeno igualmente constatado por FOY \& BARBER (1958). 


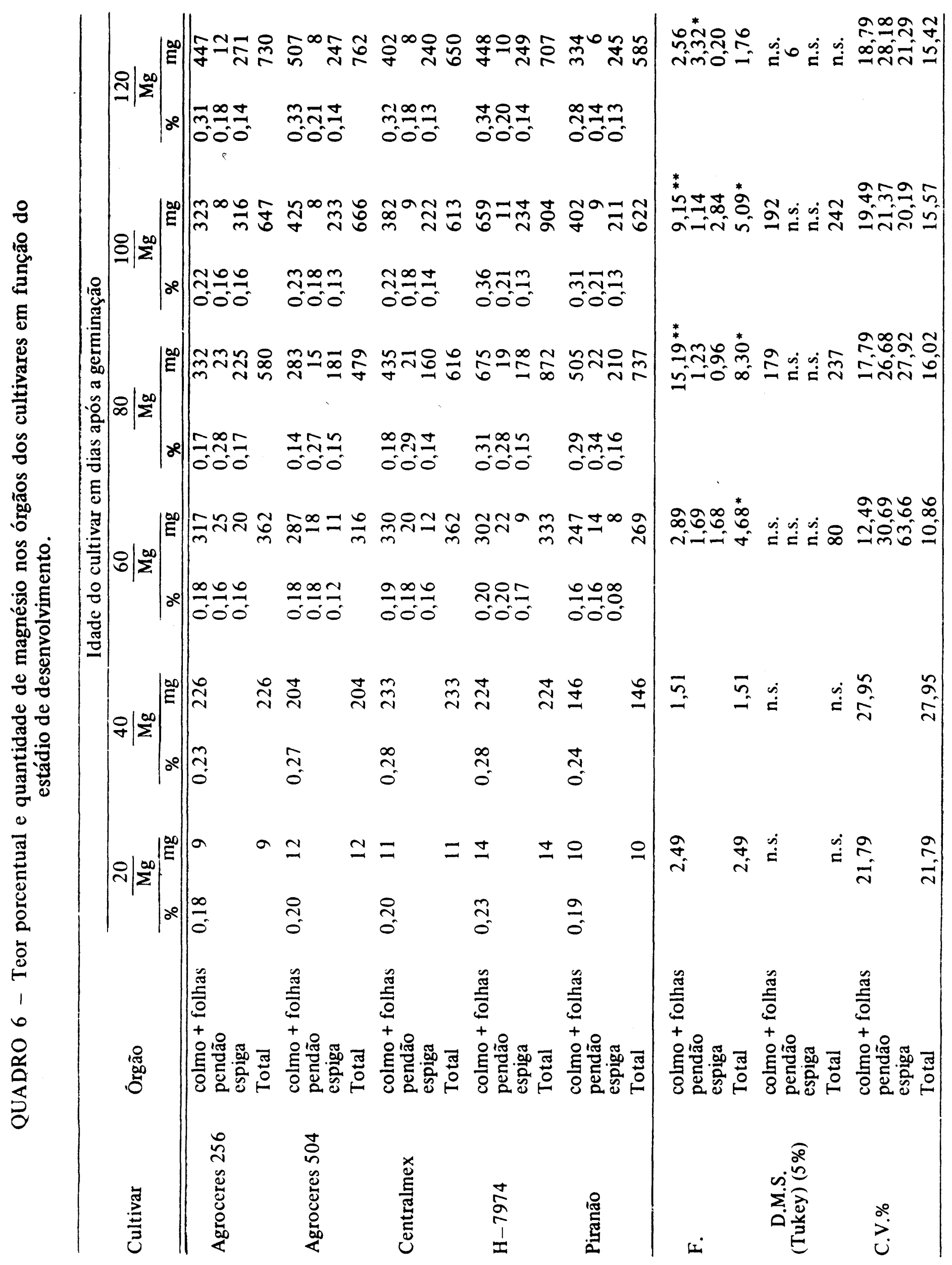




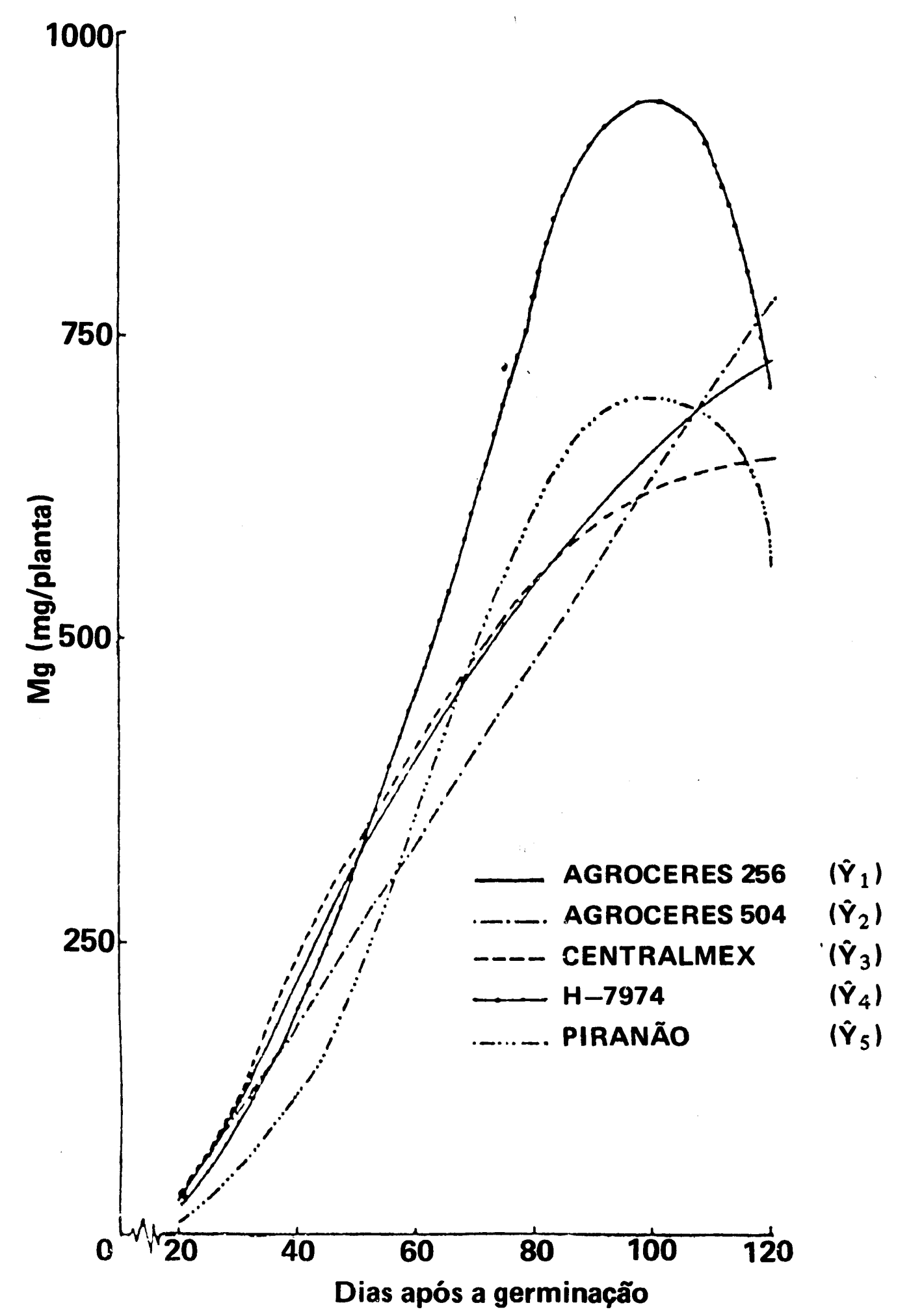

$$
\begin{array}{llll}
\hat{Y}_{1}=-240,56+13,210 X-0,0425 X^{2} & \left(r^{2}=0,92\right) \\
\hat{Y}_{2}=-123,32+7,574 X \quad\left(r^{2}=0,93\right) & \\
\hat{Y}_{3}=-287,24+15,672 X-0,0652 X^{2} & \left(r^{2}=0,92\right) \\
\hat{Y}_{4}=+323,74-27,608 X+0,738 & X^{2}-0,004 x^{3} & \left(r^{2}=0,90\right) \\
\hat{Y}_{5}=+158,95-15,985 X+0,484 & x^{2}-0,0027 x^{3} & \left(r^{2}=0,87\right)
\end{array}
$$

Figura 6 - Curvas de regressão da quantidade de magnésio $(\widehat{Y})$ em função da idade (X) nos cultivares. 


\section{Enxofre}

Os dados analiticos referentes à quantidade e porcentagem de $\mathrm{S}$ nos órgãos dos cultivares encontram-se no Quadro 7.

Pelos valores de $\mathrm{F}$ encontrados, viu-se que as diferenças entre cultivares só apareceram em épocas mais tardias. A parte vegetativa apresentou diferenças, ao nivel de $1 \%$ de probabilidade, aos 80 dias, entre os cultivares Agroceres 504 e todos os outros, e aos 100 dias entre aquele e o H-7974 e Piranão. A quantidade total mostrou diferenças ao nivel de $5 \%$ entre os mesmos cultivares, exceto para o Centralmex, que não apresentou diferença aos 80 dias, mas o fez aos 100.

A análise de regressão mostrou que as curvas correspondentes aos cultivares Centralmex, Agroceres 256 e H-7974 foram muito semelhantes, enquanto a do Agroceres 504 destacou-se bastante dos demais e os pontos para o Piranão são inferiores. As curvas e equações acham-se na Figura 7. Todos os cultivares seguiram equações do 30 grau.

A quantidade máxima de $\mathrm{S}$ nas plantas ocorreu em todos os cultivares em épocas bastante semelhantes. Contudo, as quantidades foram muito diferentes. Esses dados, e a idade em que ocorreu o ponto de inflexão, estão representados a seguir:

\begin{tabular}{lccc}
\hline Cultivar & $\begin{array}{c}\text { Ponto de máximo } \\
\text { (dias) }\end{array}$ & $\begin{array}{c}\text { Quantidade máxima } \\
\text { (mg/planta) }\end{array}$ & $\begin{array}{c}\text { Ponto de inflexão } \\
\text { (dias) }\end{array}$ \\
\hline Agroceres 256 & 95 & 552 & 56 \\
Agroceres 504 & 94 & 799 & 60 \\
Centralmex & 94 & 553 & 57 \\
H-7974 & 95 & 538 & 58 \\
Piranão & 93 & 444 & 54 \\
\hline
\end{tabular}

Em relação aos outros nutrientes, os cultivares que apresentaram menor quantidade de $\mathrm{Ca}$ e $\mathrm{Mg}$, tinham maior quantidade de $\mathrm{S}$, o que sugere um antagonismo entre estes ions divalentes.

FERRARI \& RENOSTO (1972), verificaram que o sistema de transporte de S da raiz para a parte aérea é geneticamente controlada.

É possivel que o cultivar Agroceres 504 (opaco-2) tenha maior capacidade de acumulação de $\mathrm{S}$, embora este fato necessite de confirmação, porque no final do ciclo, a diferença constatada antes, não foi encontrada. 







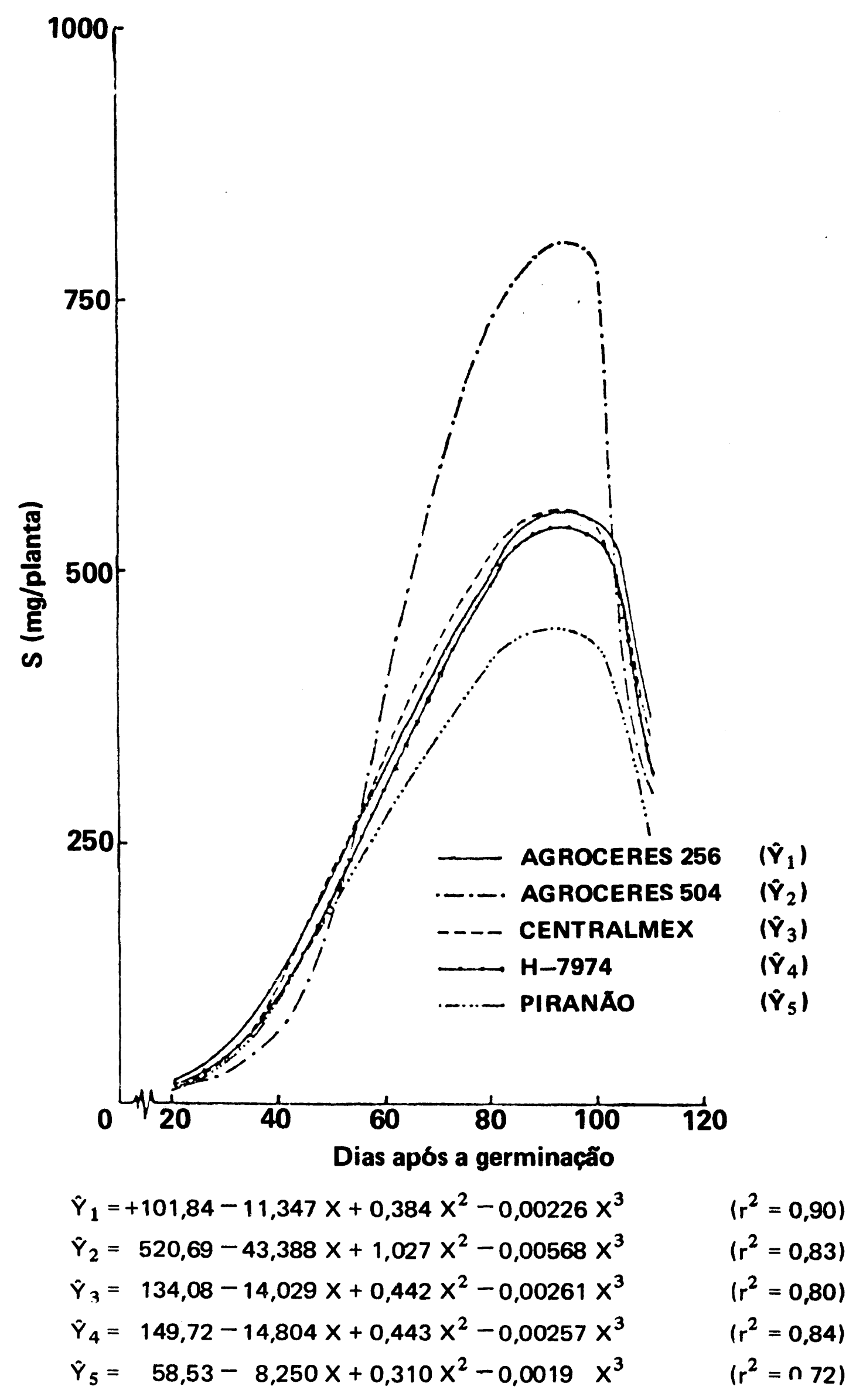

Figura 7 - Curvas de regressão da quantidade de enxofre $(\hat{\mathbf{Y}})$ em função da idade (X) nos cultivares. 


\section{Produção de grăos}

Os dados referentes à produção de grãos pelos cultivares acham-se no Quadro 8. QUADRO 8 - Produção de grãos, $15 \%$ de umidade, em $\mathrm{g} / \mathrm{planta}$ e $\mathrm{kg} / \mathrm{ha}$, dos cultivares e o rendimento dos grãos (PG/PE).

\begin{tabular}{|c|c|c|c|c|c|}
\hline \multirow{2}{*}{ Cultivar } & \multirow{2}{*}{$\begin{array}{c}\text { Amplitude de variação } \\
\mathrm{g} / \text { planta }\end{array}$} & \multicolumn{2}{|c|}{ Média de produção } & \multirow{2}{*}{$\frac{\text { Peso da espiga }}{\text { g/planta }}$} & \multirow{2}{*}{$\frac{\text { Relação }}{\text { PG/PE** }}$} \\
\hline & & $\mathrm{g} /$ planta & $\mathrm{kg} / \mathrm{ha}^{*}$ & & \\
\hline Agroceres 256 & $90,44-135,04$ & 112,5 & 5627,2 & 154,0 & 0,73 \\
\hline Agroceres 504 & $96,16-130,13$ & 118,3 & 5915,8 & 152,3 & 0,78 \\
\hline Centralmex & $122,80-167,04$ & 133,5 & 6677,4 & 179,7 & 0,74 \\
\hline H-7974 & $107,32-142,69$ & 125,7 & 6287,1 & 165,3 & 0,76 \\
\hline Piranão & $113,74-143,86$ & 128,3 & 6413,5 & 176,5 & 0,72 \\
\hline
\end{tabular}

* 50.000 plantas/ha.

** Peso da espiga é tomado como peso dos grãos + sabugo + palha da espiga.

\begin{tabular}{lrc}
\hline F. & 0,77 & 0,83 \\
D.M.S. (Tukey) (5\%) & n.s. & n.s. \\
C.V.\% & 15,31 & 14,73 \\
\hline
\end{tabular}

PG = peso dos grãos; $\quad \mathrm{PE}^{* *}=$ peso da espiga.

Verificou-se pela análise estatistica, que não houve efeito significativo para os cultivares. Contudo, pode-se notar que os cultivares Centralmex e Piranão lideraram a produção, enquanto o Agroceres 256 deu a menor média de produção de grãos. O Agroceres 504, embora apresentando o gene opaco-2 em seu genoma, o que normalmente diminui a produção de grão (CIMMYT, 1972), apresentou produção razoável e superior ao Agroceres 256.

A variação entre parcelas foi razoável, embora a análise dos blocos não tenha revelado diferenças significativas.

Comparando-se as produções obtidas com as registradas para os mesmos cultivares em outros ensaios, verificou-se que o cultivar Piranão deu produção maior que a esperada, quando comparada com a dos outros cultivares. Isto tambẻm deve ter ocorrido para Agroceres 504 (PATERNIANI, 1973; LEITE \& PATERNIANI, 1973; CIMMYT, 1972), enquanto os outros cultivares foram iguais ou um pouco abaixo do que registra PATERNIANI (1971); TAVARES \& ZINSLY (1972) e MIRANDA (1966). Contudo, GALVÃO (1973), encontrou, no mesmo ano e municipio em que foi realizado o presente trabalho, produções inferiores às conseguidas, para o Centralmex, Piranão e Agroceres 257.

É provável que a irregularidade das chuvas tenha favorecido o Piranão em relação aos demais, devido à presença do gene $\mathrm{br}_{2}$ (TREGUBEMCO \& NEPOMNACIS, 1971).

LEITE \& PATERNIANI (1973), trabalhando no ano agrícola 1972/73 e aplicando $180 \mathrm{~kg}$ de $\mathrm{N}, 120 \mathrm{~kg}$ de $\mathrm{P}_{2} \mathrm{O}_{5}$ e $60 \mathrm{~kg}$ de $\mathrm{K}_{2} \mathrm{O}$ por ha, obtiveram produções de 6255 , 
5637 e $5342 \mathrm{~kg} / \mathrm{ha}$, respectivamente para os cultivares Agroceres 257, Piranão e Centralmex, o que sugere que as percentagens de $\mathrm{N}$ encontradas nas folhas, no presente ensaio, não foram limitantes.

Pelos resultados obtidos, e pelos registros de produção encontrados, pode-se afirmar que, nas condições em que o presente ensaio foi realizado, os cultivares têm capacidade de produção semelhantes, concordando com os dados de acumulação de matéria seca (Quadro 1).

O rendimento de grãos (peso dos grãos/peso da espiga) foi inferior ao que é citado na literatura, porque no peso da espiga foi computado o peso da palha, o que não é feito normalmente.

Os cultivares apresentaram-se da seguinte ordem decrescente de rendimento: Agroceres $504>$ H-7974 $>$ Centralmex $>$ Agroceres 256 > Piranão.

\section{Exportação de nutrientes}

Os dados referentes ao teor e quantidade de macronutrientes nas espigas acham-se no Quadro 9.

É interessante assinalar que o cultivar Agroceres 504 (opaco-2) apresentou teores mais elevados em N, P, K, S que os outros cultivares, fato já observado por GOODSELL (1968), em relação ao K, o qual sugeriu que o controle se deve ao sistema de genes responsáveis pelo caráter opaco. $\mathrm{O}$ mesmo não se pode afirmar para os outros nutrientes por falta de maiores informações.

Em relação a "palha + sabugo", encontrou-se diferenças significativas, ao nivel de $1 \%$ para $\mathrm{K}$ e $\mathrm{Ca}$.

Em relação ao $\mathrm{K}$, os dados sugerem um controle genético na distribuição dentro da espiga, além do provável controle sobre a quantidade total. Os cultivares Agroceres 504 e Piranão apresentaram quantidades totais semelhantes, mas as quantidades nas partes são bem diferentes.

Em termos gerais, o cultivar Piranão apresentou as maiores quantidades de nutrientes na palha + sabugo, provavelmente porque apresenta maior proporção destas partes na espiga.

Quando se compara os dados obtidos com os citados na literatura, verifica-se que as percentagens de $\mathrm{N}$ e $\mathrm{K}$ estiveram acima da média, mesmo levando em conta que a maioria dos autores calcula estas percentagens em função do peso de grãos com $15 \%$ de umidade (BENNET et al., 1953; SOUBIES \& GADET, 1953; SAYRE, 1955; DEPARDON, 1952; LOUÉ, 1963; WEINMANN, 1956). 


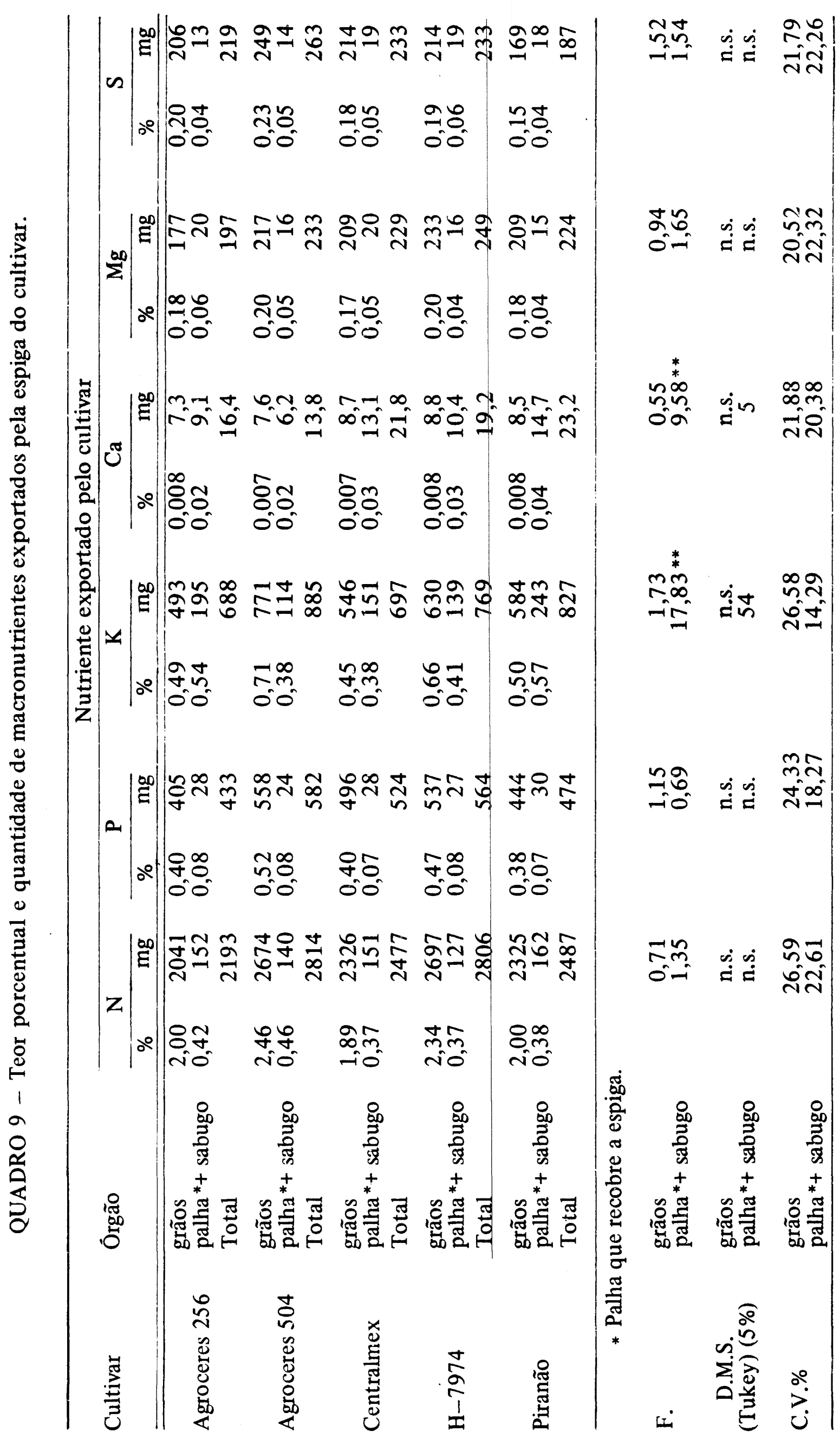


Para se avaliar a ordem de grandeza na exportação de nutrientes, em uma cultura utilizando estes cultivares, calculou-se a quantidade nas espigas para uma colheita média de $6000 \mathrm{~kg} /$ ha de grãos, para uma população de 50.000 plantas/ha.

\begin{tabular}{lc}
\hline Nutriente & Quantidade exportada por ha \\
\hline \hline Nitrogênio (N) & $111-143 \mathrm{~kg}$ \\
Fósforo (P) & $22-30 \mathrm{~kg}$ \\
Potássio (K) & $30-45 \mathrm{~kg}$ \\
Cálcio (Ca) & $0,7-1,1 \mathrm{~kg}$ \\
Magnésio (Mg) & $10-12 \mathrm{~kg}$ \\
Enxofre (S) & $9-13 \mathrm{~kg}$ \\
\hline
\end{tabular}

Em termos gerais, pode-se afirmar que, mesmo se os cultivares absorverem quantidades diferentes de nutrientes, a sua exportação através das espigas foi similar. Alẻm disso, por estes dados pode-se concluir que a adubação nitrogenada requerida para estes cultivares deve ser mais elevada que os $80 \mathrm{~kg} / \mathrm{ha}$ recomendados atualmente, em se considerando terras cultivadas anualmente com milho.

Deve-se atentar para as exportações relativamente altas de $\mathrm{Mg}$ e $\mathrm{S}$, especialmente no Estado de São Paulo, onde já se encontrou respostas significativas em relação ao $\mathrm{S}$ para produção de milho (GALLO et al., 1968).

\section{CONCLUSÕES}

\section{Crescimento}

- Os cultivares apresentam quantidades máximas de matéria seca variando entre 327 a 381 g por planta, com a idade de 100 a 106 dias.

- Diferenças entre cultivares na acumulação de matéria seca na parte vegetativa não se traduzem, necessariamente, por um aumento de peso da matéria seca na espiga.

\section{Acumulação de nutrientes}

- Não há diferenças na quantidade de N, P e K extraida pelos cultivares, embora na fase de crescimento intenso possa aparecer diferenças na quantidade destes nutrientes por planta.

- São detectadas diferenças na acumulação de $\mathrm{Ca}, \mathrm{Mg}$ e $\mathrm{S}$ quando os cultivares apresentam quantidades destes nutrientes próximas ao máximo. O cultivar $\mathrm{H}-7974$ apresenta quantidades mais elevadas de $\mathrm{Ca}$ e $\mathrm{Mg}$ que os outros, enquanto o Agroceres 504 é mais rico em $\mathrm{S}$ que os outros cultivares.

- A seleção voltada para a obtenção de plantas, simplesmente mais produtivas deve, salvo casos especificos, levar a plantas com exigências nutricionais semelhantes. 
- Os cultivares atingem o máximo da quantidade de nutrientes nas seguintes épocas (em dias): N (89-100); P (101-120); K (58-66); Ca (75-94); Mg (100-120); $\mathrm{S}(93-95)$.

- As quantidades máximas extraidas pelos cultivares estão dentro dos limites (em $\mathrm{mg} / \mathrm{planta}): \mathrm{N}$ (3169-3878); P (541-642); K (3850-4693); Ca (582-782); $\mathrm{Mg}$ (654-943); S (444-799).

\section{Produção}

- Não há diferenças entre cultivares em relação à produção de grãos. $O$ rendimento (peso de grãos/peso da espiga) obedece a seguinte ordem decrescente para os cultivares: Agroceres 504, H-7974, Centralmex, Agroceres 256 e Piranão.

\section{Exportação de nutrientes}

- Não há diferenças na quantidade de nutrientes exportada nos grãos dos cultivares.

- Além da diferença na quantidade de nutrientes translocada para a espiga, pode haver diferenças na distribuição dentro da espiga.

- A exportação de nutrientes nas espigas dos cultivares são da seguinte ordem (por hectare colhido): $\mathrm{N}(111-143 \mathrm{~kg}) ; \mathrm{P}(22-30 \mathrm{~kg}) ; \mathrm{K}(30-45 \mathrm{~kg}) ; \mathrm{Ca}(0,7-1,1 \mathrm{~kg})$; $\mathrm{Mg}(10-12 \mathrm{~kg}) ; \mathrm{S}(9-13 \mathrm{~kg})$.

SUMMARY

\section{DIFFERENTIAL ACCUMULATION OF NUTRIENTS BY FIVE CULTIVARS OF CORN (Zea mays L.). I - MACRONUTRIENTS ACCUMULATION}

The objective of the present work was to examine the differences in growth, yield, accumulation and transport of nutrients between the cultivars Agroceres 256, Agroceres 504, Centralmex, H-7974 and Piranão. The experiment was carried out in the municipality of Piracicaba, State of São Paulo, Brazil. The soil type was a sandy oxisol of medium fertility, expect for $\mathrm{K}$ which was low. The experimental set-up was a randon block design with four replications. Common cultivation practices were followed, and the fertilizer used consisted of $83 \mathrm{~g}$ of a formula: 30-120-70, per meter length at planting, and $33 \mathrm{~g}$ of the formula: 50-0-45 per meter length as dressing 22 days after germination. The plant population density was 50,000 per hectare. Plants were collected for analysis at 20 days after germination, and there after at intervals of 20 days up to 120 days. The plants were divided into "stems + leaves", tassels, and ears for chemical analysis of $\mathrm{N}, \mathrm{P}, \mathrm{K}, \mathrm{Ca}, \mathrm{Mg}$ and $\mathrm{S}$. 


\section{Conclusions:}

\section{Growth}

- The cultivars produce maximum quantities of dry matter of 327 to $381 \mathrm{~g}$ per plant at the age of 100 to 106 days.

- Differences between cultivars in terms of dry matter accumulation in the vegetative parts of the plant is not necessarily relate to the dry weight of the ear.

\section{Accumulation of nutrients}

- There are no differences in the quantity of $\mathrm{N}, \mathrm{P}$ and $\mathrm{K}$ taken-up by the cultivars, although during the period of rapid growth some differences may appear.

- Differences in the accumulation of $\mathrm{Ca}, \mathrm{Mg}$ and $\mathrm{S}$ are detected when the quantities of these nutrients approach the maximum. The cultivar $\mathrm{H}-7974$ presented the highest quantities of $\mathrm{Ca}$ and $\mathrm{Mg}$ where as Agroceres 504 was richest in S.

- The maximum level of nutrients are attained in the following period in days: $\mathrm{N}(89-100)$; P (101-120); K (58--66); Ca (75-94); Mg (100-120) and S (93-95).

-. The maximum quantities taken-up in $\mathrm{mg} /$ plant are: $\mathrm{N}(3,169-3,878) ; \mathrm{P}(541-642)$; $\mathrm{K}(3,850-4,693)$; Ca (582-782); Mg (654-943); S (444-799).

Yield

- No differences were found between cultivars for grain production.

\section{Transport of nutrients}

- There were no differences in the amounts of nutrients in the grain between cultivars.

- The transport of nutrients into the ears of the different cultivars are the following order (per hectare harvested, 50,000 plants): $\mathrm{N}(111-143 \mathrm{~kg}) ; \mathrm{P}(22-30 \mathrm{~kg})$; $\mathrm{K}(30-45 \mathrm{~kg}) ; \mathrm{Ca}(0.7-1.1 \mathrm{~kg}) ; \mathrm{Mg}(10-12 \mathrm{~kg})$ and $\mathrm{S}(9-13 \mathrm{~kg})$.

\section{LITERATURA CITADA}

ADELANA, B.O. \& MILBOLRN, G.M., 1972. The growth of maize. II. Dry matter partition in three maize hybrids. J. Agric. Sci., 78:73-78.

ASHBURN, E.L., 1971. The yield and uptake of nutrierits by selected corn genotypes as influenced by nitrogen fertilization. Dissert. Abst. Intern. B, 32:33.

BAKER, E.E., BRADFORD, B.R. \& THOMAS, W.I., 1966. Leaf analysis of corntool for predicting soil fertility needs. Better Crops Plant Food., 50:36-40. 
BAKER, D.E., BRADFORD, B.R. \& THOMAS, W.I., 1967. Accumulation of Ca, Sr., Mg, P and $\mathrm{Zn}$ by genotypes of corn (Zea mays L.), under different soil fertility levels. Isotopes in Plant Nutrition and Physiology. Proc. Symp. FAO/IAEA, Vienna, 1966.

BARBER, S.A., 1968. Mechanism of potassium absorption by plants. IN:Kilmer, V.J. et al. (eds.). The role of potassium in agriculture. American Society of Agronomy, Inc.; Madison, Wis., p. 293-310.

BARRIGA BEZANILLA, G.P., 1971. A eficiência de alguns cultivares de milho (Zea mays L.) na produção de grãos. Piracicaba, SP. 84 pp. Dissertação (mestre). ESALQ.

BENNET, W.F., STANFORD, G. \& DUMENIL, L., 1953. Nitrogen, phosphorus and potassium content of the corn leaf and grain as related to nitrogen fertilization and yield. Soil Sci. Soc. Amer. Proc., $17: 252-258$.

BRADFORD, R.R., BAKER, D.E. \& THOMAS, W.I., 1966. Effect of soil treatments on chemical element accumulation of four corn hybrids. Agron. J., 58.614-617.

CLARK, R.B. \& BROWN, J.C., 1974a. Internal root control of iron uptake and utilization in maize genotypes. Plant and Soil, 40.667-677.

CIMMYT, 1972. Informe Anual. El Batan, México.

DEPARDON-MAUVISSEAU, B., 1952. Besoins en elements fertilisants des mais hybrides. C.R. Ac. Agr., 38:143-145.

DUNCAN, W.G., 1967. Corn yield to meet the challenge. IN : Maximum crop yield - the challenge. American Society of Agronomy (publicação especial nọ 9), Madison, Wis., p. 51-56.

DYNARD, T.B., TANNER, J.W. \& DUNCAN, W.G., 1971. Duration of grain filling period and its relation to grain yield in corn (Zea mays L.). Crop Sci., $11: 45-48$.

EPSTEIN, E., 1972. Mineral nutrition of plants: principles and perspectives. John Wiley and Sons. Inc., New York, London. 412 pp.

EPSTEIN, E. \& JEFFERIES, R.L., 1964. The genetic basis of seletive ion transport in plants. Ann. Rev. Plant Physiol., $15: 169-184$.

FERRARI, G. \& RENOSTO, F., 1972. Comparative studies on active transport by excised roots of imbred and hybrid maize. J. Agri. Sci., 79 :105-108.

FOY, C.D. \& BARBER, S.A., 1958. Magnesium absorption and utilization by two imbred lines of corn. Soil Sci. Soc. Amer. Proc., 22:57-62.

GALLO, J.R., HIROCE, R. \& DE MIRANDA, L.T., 1968. A análise foliar na nutrição do milho. I. Correlação entre análise de folhas e produção. Bragantia, $27: 177-186$.

GALVÃO, J.D., 1973. Comportamento do milho Piranão (braquítico - 2) e de milhos de porte normal em diferentes níveis de nitrogênio e populações de plantas. Piracicaba, SP. 106 pp. Tese (doutor) - ESALQ.

GOODSELL, S.F., 1968. Potassium levels in mature seeds of normal and opaque - 2 maize. Crop Sci., $8: 281-282$.

GORSLINE, G.W., RAGLAND, J.L. \& THOMAS, W.I., 1961. Evidence for inheritance of differential accumulation of calcium, magnesium and potassium by maize. Crop Sci., 1:155-156.

GORSLINE, G.W., THOMAS, W.I. \& BAKER, D.E., 1964. Inheritance of P, K, Mg, Cu, B, $\mathrm{Zn}$, $\mathrm{Mn}, \mathrm{Al}, \mathrm{Fe}$ concentration by corn (Zea mays L.) leaves and grain. Crop Sci., 4 :207-210.

HANWAY, D.G., 1967. Irrigation. IN: Pierre, W.H. et al. (eds.). Advances in corn production: principles and practices. The Iowa State University Press. AMES, Iowa., p. 155-175.

HANWAY, J.J., 1962a. Corn growth and composition in relation to soil fertility. I. Growth of different plant parts and relation between leaf weight and grain yield. Agron. J., 54:145-148.

HANWAY, J.J., 1962b. Corn growth and composition in relation to soil fertility. II. Uptake of N, $P$ and $K$ and their distribution in different plant parts during the growing season. Agron. J., 
$54: 217-222$.

HANWAY, J.J. \& RUSSEL, W.A., 1969. Dry-matter accumulation in corn plants: comparisons among single-cross hybrids. Agron. J., 61:947-951.

JENNE, E.A., RHOADES, H.F., YIEN, C.H. \& HOWE, O.W., 1958. Change in nutrient element accumulation by corn with depletion of soil moisture. Agron. J., 50:71-74.

-JONES, W.J., Jr. \& HUSTON, H.A., 1914. Composition of maize at various stages of its growth. Indiana Agr. Expt. Sta. Bull. 175.

KOLLER, O.L. \& MUNSTOCK, C.M., 1972. Distribuição da matéria seca, na planta durante o período de formação dos grãos, em seis cultivares de milho. Anais da IX Reunião Brasileira de Milho. Recife, p. 150-158.

KRUG, C.A., 1966. O milho no mundo. IN : Cultura e adubação do milho. Instituto Brasileiro de Potassa (ed.). São Paulo, SP, p. 11-19.

LEITE, D.R. \& PATERNIANI, E., 1973. Comportamento de milho (Zea mays L.) braquítico-2 em diferentes densidades de plantio. Relatório Científico do Instituto de Genética - E.S.A. "Luiz de Queiroz", Piracicaba, 7:74-82.

LIEBHARDT, W.C., 1968. Effect of potassium on carbohidrate metabolism and translocation. IN: Kilmer, V.J. et al. (eds.). The role potassium in agriculture. American Society of Agronomy, Inc., Madison, Wis., p. 147-164.

LOUÉ, A., 1963. Estudo comparativo das exigências minerais de algumas variedades de milho híbrido. Fertilité, 20:22-32.

MALAVOlTA, E., HAAG, H.P., MELlO, F.A.F. \& BRASIL SOBRo, M.O.C., 1974. Nutrição mineral e adubação de plantas cultivadas. Liv. Pioneira editora, São Paulo. 727 pp.

MENGEL, K., 1968. Exchangeable cations of plant roots and potassium absorption by the plant. IN : Kilmer, V.J. et al. (eds.). The role of potassium in agriculture. American Society of Agronomy, Inc. Madison, Wis., p. 311-320.

MIRANDA, L.T., 1966. Híbridos e variedades. IN: Cultura e adubação do milho. Instituto Brasileiro da Potassa (ed.). São Paulo, p. 153-173.

NELSON, L.B., 1956. The mineral nutrition of corn as related to its growth and culture. Adv. Agron., 8:321-375.

NELSON, W.L., 1968. Plant factors affecting potassium availability and uptake. IN: Kilmer, V.J. et al. (eds.). The role of potassium in agriculture. American Society of Agronomy, Inc. Madison, Wis., p. 355-384.

NEPTUNE, A.M.L., 1966. Estudos sobre adubação e diagnose foliar do milho (Zea mays L.). Piracicaba, SP. 167 pp. Tese (cátedra) - ESALQ.

OLSON, R.A. \& LUCAS, R.E., 1967. Fertility requirement: secundary and micronutrients. IN: Pierre, W.H. et al. (eds.). Advances in corn production: principles and practices. The Iowa State University Press. Ames, Iowa., p. 285-330.

PATERNIANI, E., 1973. Origem e comportamento do milho Piranão. Relatório Científico do Instituto de Genética - E.S.A. "Luiz de Queiroz", Piracicaba, 7:148-160.

PEASLEE, D.E., RAGLAND, J.L. \& DUNCAN, W.G., 1971. Grain filling period of corn as influenced by phosphorus, potassium and the time of planting. Agron. J., 63:561-563.

PESEK, J., 1968. Potassium nutrition of soybeans and corn. IN: Kilmer, V.J. et al. (eds.). The role of potassium in agriculture. American Society of Agronomy, Inc. Madison, Wis., p. 447. $-468$.

RANZANI, G., 1956. Levantamento da carta de solo da Secção Técnica "Química Agrícola" da Escola Superior de Agricultura "Luiz de Queiroz". Piracicaba, SP. Tese (livre-docente) ESALQ. 
ROBERTSON, W.K., THOMPSON, L. \& HAMMOND, L.C., 1968. Yield and nutrient removal by corn (Zea mays $\mathrm{L}$.) for grain as influenced by fertilizer, plant population, and hybrid. Soil Sci. Amer. Proc., 32:245-249.

SARRUGE, J.R. \& HAAG, H.P., 1974. Análises químicas em plantas. Piracicaba, SP. Departamento de Química, ESALQ (publicação especial).

SAYRE, J.D., 1948. Mineral accumulation in corn. Plant Physiol., 23 267-281.

SAYRE, J.D., 1955. Mineral nutrition of corn. IN : Sprague, G.F. (ed.). Corn and corn improvement. Academic Press, Inc., New York, N.Y., p. 293-314.

SOUBIES, L. \& GADET, R., 1953. L'exportation d'élément fertilisants par le mais. C.R. Ac. Agr., $39: 176-178$.

TAVARES, F.C. \& ZINSLY, J.R., 1972. Componentes da produção relacionados à heterose em híbridos intervarietais de milho (Zea mays L.). Relatório Científico do Instituto de Genética da E.S.A. "Luiz de Queiroz", Piracicaba, 6 96-116.

TREGUBEMCO, M.J. \& NEPOMNACIS, V.I., 1971. The water consumption of brachytic maize hybrids in relation to their yields. APUD: Plant Breeding Abst., vol. 41, no 2, p. 340.

VIETS, F.G., 1962. Fertilizers and the efficient use of water. Adv. Agron., 14 :223-264.

VOSE, P.B., 1963. Varietal differences in plant nutrition. Herb. Abst., 33:1-13.

VEINMANN, H., 1956. Studies on the chemical composition and nutrient uptake of maize. Rhod. Agr. J., $53: 168-181$. 
